\title{
Genome-wide survey of yeast mutations leading to activation of the yeast cell integrity MAPK pathway: Novel insights into diverse MAPK outcomes
}

\author{
Patricia Arias, Sonia Díez-Muñiz, Raúl García, César Nombela, José M Rodríguez-Peña* and Javier Arroyo
}

\begin{abstract}
Background: The yeast cell wall integrity mitogen-activated protein kinase (CWI-MAPK) pathway is the main regulator of adaptation responses to cell wall stress in yeast. Here, we adopt a genomic approach to shed light on two aspects that are only partially understood, namely, the characterization of the gene functional catalog associated with CWI pathway activation and the extent to which MAPK activation correlates with transcriptional outcomes.

Results: A systematic yeast mutant deletion library was screened for constitutive transcriptional activation of the CWIrelated reporter gene MLP1. Monitoring phospho-Slt2/Mpk1 levels in the identified mutants revealed sixty-four deletants with high levels of phosphorylation of this MAPK, including mainly genes related to cell wall construction and morphogenesis, signaling, and those with unknown function. Phenotypic analysis of the last group of mutants suggests their involvement in cell wall homeostasis. A good correlation between levels of SIt2 phosphorylation and the magnitude of the transcriptional response was found in most cases. However, the expression of CWI pathway-related genes was enhanced in some mutants in the absence of significant Slt2 phosphorylation, despite the fact that functional MAPK signaling through the pathway was required. CWI pathway activation was associated to increased deposition of chitin in the cell wall - a known survival compensatory mechanism - in about 30\% of the mutants identified.

Conclusion: We provide new insights into yeast genes related to the CWI pathway and into how the state of activation of the SIt2 MAPK leads to different outcomes, discovering the versatility of this kind of signaling pathways. These findings potentially have broad implications for understanding the functioning of other eukaryotic MAPKs.
\end{abstract}

\section{Background}

The capacity to respond properly to external stimuli or environmental conditions is essential for homeostasis in eukaryotes. Signaling pathways, in particular those mediated by mitogen-activated protein kinases (MAPKs), play a key role in these processes. A significant amount of research has been conducted in recent years to characterize these signal transduction pathways, based largely on the model yeast Saccharomyces cerevisiae (also known as baker's or budding yeast). Since MAPK pathways are evolutionarily conserved, insights gained from yeast contribute to a better understanding of orthologous pathways in higher organisms. The basic assembly of MAPK

\footnotetext{
* Correspondence: josemanu@farm.ucm.es

Departamento de Microbiología II, Facultad de Farmacia, Universidad Complutense de Madrid, IRYCIS, 28040 Madrid, Spain
}

pathways is a three-component module conserved from yeast to humans, consisting of three kinases that establish a sequential activation pathway by means of phosphorylation events [1]. The regulation of MAPK signal transduction depends on a variety of mechanisms including scaffold proteins, subcellular localization of different elements and the action of protein phosphatases [2].

In yeast, six MAPK cascades have been identified that mediate the response to different stimuli: (i) pheromones (pheromone response pathway); (ii) nitrogen starvation (filamentous growth pathway); (iii) hyperosmolarity (high osmolarity/glycerol pathway); (iv) STE vegetative growth pathway (SVG) [3]; (v) nutrient starvation (spore wall assembly pathway); and (vi) cell wall stress (CWI: cell wall integrity pathway) (see an extensive review of MAPK pathways in [2]). The CWI pathway is essential for maintaining
C Biomed Central

(c) 2011 Arias et al; licensee BioMed Central Ltd. This is an Open Access article distributed under the terms of the Creative Commons Attribution License (http://creativecommons.org/licenses/by/2.0), which permits unrestricted use, distribution, and reproduction in any medium, provided the original work is properly cited. 
cellular integrity. Therefore, mutations affecting different elements of the pathway lead to cell lysis $[4,5]$. The maintenance of cellular integrity and morphology, as well as the protection of the cell from adverse environmental conditions, depends on the cell wall, an essential structure that has been characterized extensively in Saccharomyces cerevisiae (reviewed in $[6,7]$ ). It has three major components: an inner layer of glucans ( $\beta-1,3$ and $\beta-1,6$-glucan), chitin and an outer layer of mannoproteins. These components must be correctly assembled in order to build a fully functional structure $[6,8,9]$.

The essentiality of the cell wall for fungal viability makes it one of the most attractive targets for therapeutic intervention against fungal pathogens [10]. Treatment with cell wall-perturbing agents such as the chitin-binding dyes Congo red and Calcofluor white or zymolyase, which degrades the $\beta$-1,3-glucan network, elicits a cellular survival response known as "compensatory mechanism" [11]. This adaptive response includes changes in the yeast transcriptional program that we and other groups have characterized, not only in yeast mutants affected at different stages of cell wall biosynthesis [12], but also in wild-type yeast cells growing under different conditions causing transient cell wall damage [13-18]. The compensatory response leads to, among other effects, an increase in the amount of $\beta$-glucan and chitin, the production of several cell wall proteins and changes in the cross-linking between cell wall polymers [19]. Although several signaling pathways contribute to the regulation of cell wall remodeling in order to ensure cell integrity, the regulation of this compensatory response is controlled mainly by the MAPK Slt2p/Mpk1p (hereafter noted as Slt2p) through the cell wall integrity pathway (for a review, see [20,21]). The CWI pathway is regulated through the cell cycle, being also activated in response to a variety of external stimuli and morphological events that cause cell wall stress, such as heat stress, hypo-osmotic shock, mating pheromones, oxidative stress, actin depolymerization, cell wall-related mutations, cell wall-stressing agents, alkaline stress and endoplasmic reticulum (ER) stress [20,22-25].

Several cell membrane proteins (Mid2, Wsc1-4 and Mtl1) [26-28] act as sensors of the CWI pathway. For further intracellular transduction of the activation signal, these sensors interact with the guanine nucleotide exchange factor (GEF) Rom2, activating the small GTPase Rho1, which then activates the yeast protein kinase $C$ (Pkc1). The main role of activated Pkc1 is to trigger a MAPK module. Upon phosphorylation, the MAPKKK Bck1 activates a pair of redundant MAPKKs (Mkk1 and Mkk2), which phosphorylate the MAPK Slt2. Slt2 is a functional homolog of human ERK5 [29], a MAPK that is activated in response to both growth factors and physical and chemical stresses [30,31]. The dually phosphorylated $\left(\mathrm{Thr}^{190} / \mathrm{Tyr}^{192}\right.$ ) form of Slt2 activates two transcription factors: the MADS-box transcription factor Rlm1 [32] and SBF, a heterodimeric complex of two proteins, Swi4 and Swi6, which are mainly involved in the regulation of gene expression in G1/S transition [33]. Although Rlm1, activated through phosphorylation by Slt2 [34], is responsible for the transcriptional activation of the majority of the genes induced in CWI adaptation responses, a non-catalytic mechanism of transcriptional activation mediated by SBF through Slt2 has recently been described [35]. This alternative mechanism extends the regulatory roles of the MAPK cascade.

In accordance with the complexity of the cellular processes related to cell wall homeostasis in yeast, crosstalk between distinct MAPK pathways has recently been described. This complicates the simple linear "topdown" concept of signaling pathways. For example, Slt2 is activated in response to hyperosmotic shock through the HOG1 MAPK pathway [36]. Similarly, our group has shown that treating yeast cells with zymolyase also activates Slt2 in a Hog1 pathway-dependent manner $[17,37]$.

Considering that the CWI pathway is activated under cell wall stress, our working hypothesis is that yeast strains lacking genes functionally relevant for cell wall biogenesis or pathway regulation should present a constitutive activation of this route. In this paper, we describe the development of a genomic-wide screening in order to identify genes whose absence produces a functional constitutive activation of the CWI pathway of Saccharomyces cerevisiae under vegetative (non-stressed) growth conditions. As a result, we have identified, for the first time at genomic scale, a map of genes that could be functionally related to the CWI pathway. Furthermore, this report gives new insights into the link between the magnitude of MAPK activation and transcriptional induction or cell wall remodeling events. This information can be extended to pathogenic fungi, being useful for future therapeutic purposes.

\section{Results and discussion}

\section{Large-scale identification of gene deletions that activate} the cell wall integrity pathway in yeast

The CWI pathway of Saccharomyces cerevisiae, governed by the MAPK Slt2, is triggered under conditions that compromise the integrity of the cell wall. Signaling through this pathway can be monitored by taking advantage of reporters driven by $\mathrm{R} \operatorname{lm} 1$-responsive promoters. We have recently developed a transcriptional reporter system, especially suitable for large-scale studies, that potentially allows detecting the functional activation of the CWI pathway [38]. Essentially, this system is based on a plasmid construction (pJS05) that includes a transcriptional fusion of the promoter region of the $M L P 1$ gene, one of the main effectors of the transcriptional up-regulation response 
under cell wall stress, and the coding sequence of the NAT1 gene, which encodes resistance to the antibiotic nourseothricin. In other words, the expression of NAT1 is controlled by the MLP1 promoter; therefore, yeast mutants with a constitutive activation of the CWI pathway transformed with this construction should be able to grow in the presence of higher concentrations of the antibiotic than a wild-type strain.

Following this approach, we have designed a largescale screening to identify yeast deletions associated with Slt2-driven transcriptional activation. To achieve this goal, we used the collection of haploid mutant strains in all non-essential genes of Saccharomyces cerevisiae ( 4800 strains). As represented in Figure 1, we proceeded to transform this collection into a 96well microplate format with the plasmid containing $M L P 1_{P}-N A T 1$, and the transformed strains were screened for their ability to grow in the presence of $300 \mu \mathrm{g} / \mathrm{ml}$ nourseothricin. This inhibitory concentration of antibiotic was previously determined using selected mutants in which basal levels of Slt2 activation were similar to those found in a wild-type strain (data not shown). After 48-72 hours of growth in a selective medium, 174 mutant strains with hyper-resistance to nourseothricin were identified and selected for further characterization.

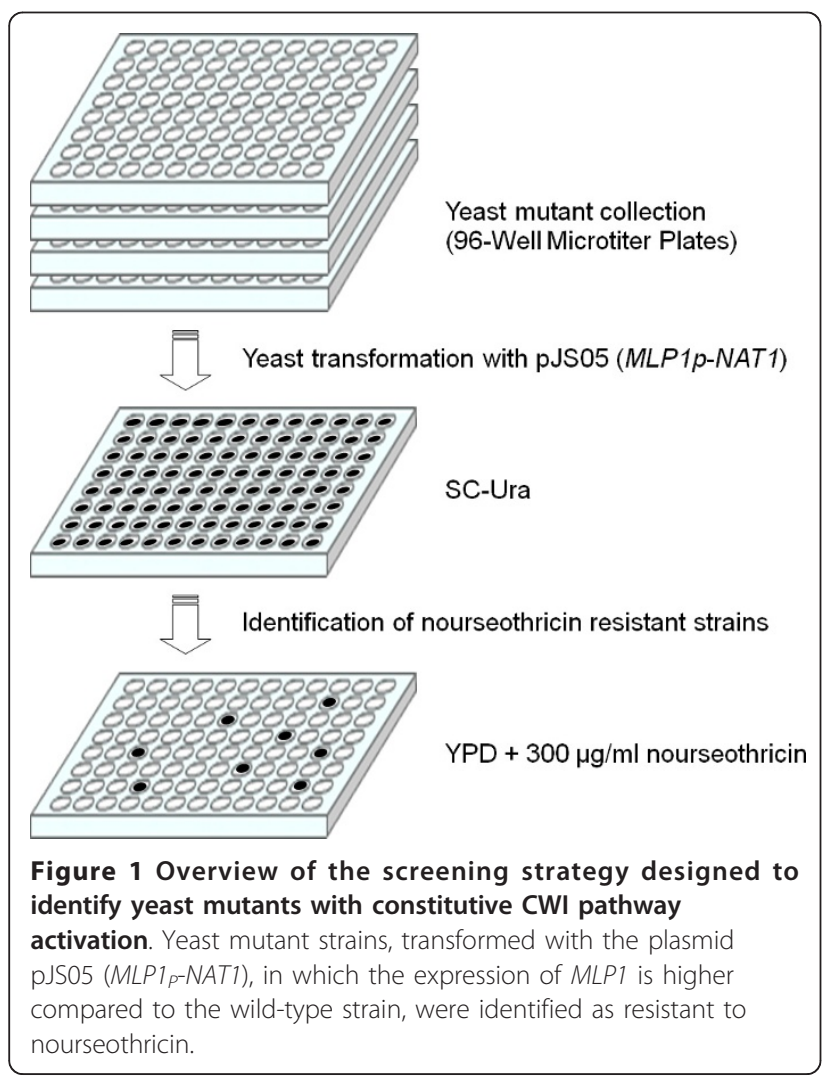

\section{Slt2 phosphorylation levels in nourseothricin-resistant mutants identified in the screening}

A reliable method for monitoring signaling through the CWI pathway is to follow the activation state of the MAPK Slt2 by using commercially available antibodies that recognize the dual phosphorylation of conserved threonine and tyrosine residues within the activation loop of Slt2, analogous to $\mathrm{Thr}^{202} / \mathrm{Tyr}^{204}$ of mammalian $\mathrm{p} 44 / \mathrm{p} 42$ MAP Kinase (ERK) [39]. In order to associate the phosphorylation status of Slt2 to MLP1 up-regulation, the 174 deletant strains formerly selected were examined following this approach. After densitometric quantification of the phospho-Slt2 bands obtained by Western blotting analysis of the total protein extracts from each mutant strain, 64 mutants recorded higher Phospho-Slt2 levels (at least twofold) than the wild-type strain. The relative amount of phospho-Slt2 in these mutants was distributed over a wide range of values (from twice to thirtyfold) (Table 1). Representative examples of Slt2 activation in different mutants are shown in Figure 2. The complete data set (Western blots) for all the selected mutants is presented in Additional file 1. These data indicate different levels of CWI pathway activation for each mutant, suggesting that yeast cells modulate pathway activation as required by specific stimuli. Remarkably, more than $20 \%$ of the mutations identified in a large-scale analysis revealing synthetic lethal interaction with slt2 $\Delta$ [40] have also been isolated in our screening (Table 1).

As shown in Table 1, the functional categorization of mutants identified for constitutive Slt2 activation revealed the most representative functional groups according to the BIOBASE Knowledge Library Proteome and Saccharomyces Genome Database classifications, being those involved in cell wall organization and morphogenesis $(28 \%)$, genes of unknown function (17\%), signal transduction (17\%), transport (11\%) and transcription (9\%). The remaining functional categories comprise mutants linked to metabolism (principally of RNA and proteins) and other cellular functions with lower representation in the screening (see Table 1). This distribution is consistent with putative inputs of the pathway, namely, cell wall alterations or regulatory proteins.

An analysis was conducted of predicted and known interactions between the whole set of genes identified in the screening using the STRING web resource (http:// string-db.org) [41]. This tool is very useful for the retrieval of an overall perspective of interacting genes/proteins. As shown in Figure 3, a large number of genes (38 out of 64) showed functional interactions between them. Interestingly, the interaction network was clustered again in the three main functional nodes (cell wall and morphogenesis, signal transduction and transcription) described above. From the large group of 18 mutants related to cell wall and morphogenesis, different subgroups can be 
Table 1 S. cerevisiae mutants with increased levels of dually phosphorylated MAP Kinase Slt2

\begin{tabular}{|c|c|c|c|c|}
\hline ORF & Gene & P-SIt2 & Functional Group & Description \\
\hline YAL058W & CNE1 & 16.4 & Cell wall and morphogenesis & Calnexin 1. may be involved in a QC process for secretory pathway proteins \\
\hline YBLOOTC & SLA1 & 8.1 & Cell wall and morphogenesis & Functions in the assembly of cortical actin cytoskeleton \\
\hline YBR078W & ECM33 & 14.4 & - Cell wall and morphogenesis & GPI-anchored protein required for CW integrity and mannoprotein biosynthesis \\
\hline YCR088W & $A B P 1$ & 2.3 & Cell wall and morphogenesis & Actin binding protein that functions in clathrin- and actin-mediated endocytosis \\
\hline YDL095W & PMT1 & 10.8 & Cell wall and morphogenesis & Mannosyltransferase, first step in O-glycosylation \\
\hline YDR349C & YPS7 & 16.6 & - Cell wall and morphogenesis & GPI-anchored aspartyl protease involved in maintaining cell wall integrity \\
\hline YJL062W & LAS21 & 3.6 & Cell wall and morphogenesis & Protein required for addition of a side chain to the GPI core structure \\
\hline YJL099W & CHS6 & 2.9 & Cell wall and morphogenesis & Protein involved in chitin synthase Chs3p activity \\
\hline YJR075W & $\mathrm{HOCl}$ & 2.1 & - Cell wall and morphogenesis & Alpha-1,6-mannosyltransferase activity \\
\hline YLR319C & BUD6 & 2.4 & Cell wall and morphogenesis & Budding 6, required for bipolar budding and involved in bud site selection \\
\hline YLR337C & VRP1 & 8.6 & Cell wall and morphogenesis & Proline-rich protein verprolin, involved in cytoskeletal organization \\
\hline YLR350W & ORM2 & 2.6 & Cell wall and morphogenesis & Putative transmembrane protein that may function in the CWI pathway \\
\hline YLR370C & ARC18 & 5.5 & Cell wall and morphogenesis & Component of the ARP $2 / 3$ actin-organizing complex, involved in actin assembly \\
\hline YMR307W & GAS1 & 27.4 & - Cell wall and morphogenesis & GPI-anchored protein with 1,3-beta-glucanosyltransferase activity \\
\hline YNL079C & TPM1 & 7.2 & - Cell wall and morphogenesis & Tropomyosin, functions in a variety of processes involving the actin cytoskeleton \\
\hline YNL116W & DMA2 & 3.4 & Cell wall and morphogenesis & Functions in spindle positioning and septin ring assembly \\
\hline YNL192W & CHS1 & 2.0 & Cell wall and morphogenesis & Chitin synthase I, has a repair function during cell separation \\
\hline YORO02W & ALG6 & 6.3 & Cell wall and morphogenesis & Dolichyl-phosphate-mannose-protein mannosyltransferase activity \\
\hline YER037W & PHM8 & 4.0 & Metabolism & Lysophosphatidic acid phosphatase \\
\hline YJL137C & GLG2 & 2.3 & Metabolism & Transferase activity, transferring hexosyl groups \\
\hline YHLO23C & RMD11 & 2.9 & Nuclear & Protein possibly involved in meiotic nuclear division \\
\hline YPR031W & NTO1 & 2.0 & Nuclear & May be involved in chromatin-mediated transcription regulation \\
\hline YBR101C & FES1 & 2.8 & Protein metabolism & NEF for the cytosolic chaperone Ssa1p. Response to oxidative stress \\
\hline YDR069C & DOA4 & 2.6 & Protein metabolism & Ubiquitin-specific protease that acts in recycling ubiquitin \\
\hline YFLO07W & BLM10 & 4.0 & Protein metabolism & Proteasome assembly \\
\hline YBLO24W & NCL1 & 5.8 & RNA metabolism & tRNA (cytosine-5-)-methyltransferase activity \\
\hline YPL029W & SUV3 & 2.0 & RNA metabolism & Mitochondrial RNA helicase of the DEAD box family \\
\hline YPL213W & LEA1 & 9.0 & RNA metabolism & RNA splicing factor activity \\
\hline YDLO47W & SIT4 & 4.3 & Signal transduction & Serine/threonine phosphatase involved in cell cycle regulation/ion homeostasis \\
\hline YDR162C & NBP2 & 16.9 & Signal transduction & Negative regulator of the HOG pathway \\
\hline YDR389W & SAC7 & 7.5 & Signal transduction & GTPase-activating protein for Rho1p \\
\hline YER155C & BEM2 & 2.4 & - Signal transduction & GTPase-activating (GAP) protein that regulates Rho1p \\
\hline YHR082C & KSP1 & 2.9 & Signal transduction & Serine/threonine kinase involved in filamentous growth \\
\hline YHR206W & SKN7 & 2.5 & Signal transduction & Transcription factor involved in the oxidative and osmotic stress responses \\
\hline YJR074W & MOG1 & 5.4 & Signal transduction & Involved in nuclear protein import, plays a role in osmoregulation via SLN1-SKN7 \\
\hline YKL126W & YPK1 & 2.3 & Signal transduction & Putative $S / T$ protein kinase possibly related with the $\mathrm{CWI}$ and sphingolipids \\
\hline YLR371W & ROM2 & 2.5 & Signal transduction & GDP-GTP exchange factor for Rho1p \\
\hline YNL053W & MSG5 & 5.4 & Signal transduction & Dual-specificity protein tyrosine phosphatase involved in response to pheromone \\
\hline YNR047W & FPK1 & 3.9 & Signal transduction & Serine/threonine protein kinase that regulates phospholipid asymmetry \\
\hline YLR242C & ARV1 & 8.6 & Sphingolipid metabolism & Protein involved in sterol uptake required for normal sphingolipid metabolism \\
\hline YER139C & RTR1 & 5.2 & Transcription & Protein required for growth at high temperature, RNA polymerase II factor \\
\hline YMR136W & GAT2 & 10.7 & Transcription & GATA zinc finger transcription factor \\
\hline YNL025C & SSN8 & 2.2 & Transcription & RNA polymerase II transcription mediator \\
\hline YPLO42C & SSN3 & 3.9 & Transcription & Cyclin-dependent serine/threonine protein kinase of the RNA polymerase II \\
\hline YPR065W & ROX 1 & 4.7 & Transcription & Transcriptional repressor of hypoxic genes \\
\hline YPR115W & & 3.6 & Transcription & Phosphoinositide binding. Response to oxidative stress \\
\hline YDR200C & VPS64 & 3.9 & Transport & Class B vacuolar sorting protein involved in Prc1p trafficking/ $\alpha$-factor secretion \\
\hline YFLO48C & EMP47 & 4.1 & Transport & Golgi and ER membrane protein involved in glycoprotein secretion \\
\hline YGR028W & MSP1 & 2.1 & Transport & Intra-mitochondrial sorting protein, member of the AAA family of ATPases \\
\hline YHRO32W & ERC1 & 3.5 & Transport & Member of the MatE family. Transporter activity \\
\hline YJL133W & MRS3 & 5.2 & Transport & Mitochondrial carrier (MCF, family of membrane transporters). Iron transport \\
\hline
\end{tabular}


Table 1 S. cerevisiae mutants with increased levels of dually phosphorylated MAP Kinase Slt2 (Continued)

\begin{tabular}{|c|c|c|c|c|}
\hline YJR152W & DAL5 & 5.7 & Transport & Member of the allantoate family of the major facilitator superfamily (MFS \\
\hline YLR292C & SEC72 & 2.9 & Transport & Component of ER protein-translocation subcomplex. \\
\hline YCRO90C & & 2.0 & Unknown & Unknown function \\
\hline YDL173W & & 4.1 & Unknown & Unknown function \\
\hline YDR290W & & 4.2 & Unknown & Unknown function \\
\hline YGR022C & & 3.9 & Unknown & Unknown function \\
\hline YLR250W & SSP120 & 5.2 & Unknown & Unknown function \\
\hline YLR338W & & 7.2 & Unknown & Unknown function \\
\hline YMR119W-A & & 3.2 & Unknown & Unknown function \\
\hline YNL058C & & 3.0 & Unknown & Unknown function \\
\hline YNL105W & & 5.5 & Unknown & Unknown function \\
\hline YNRO14W & & 2.5 & Unknown & Unknown function \\
\hline YPL158C & & 3.0 & Unknown & Unknown function \\
\hline
\end{tabular}

Levels of Slt2 phosphorylation (P-Slt2) correspond to the fold-change in each mutant strain relative to the wild-type calculated as described in Methods. Representative data of at least replicated experiments are shown. Functional categories and descriptions were assigned based on the information provided by the BIOBASE Knowledge Library Proteome. Genes were grouped together on the basis of their functional category. Those gene deletions that have been reported to be synthetic lethal with slt2 $\Delta$ are labeled with a black dot.

highlighted. The first subgroup comprises seven genes (SLA1, ABP1, BUD6, VRP1, ARC18, TPM1, DMA2) related to actin cytoskeleton organization. Actin cytoskeleton disruption has been shown to activate the CWI pathway, probably due to the induction of cell wall stress, but the precise molecular mechanism by which Slt2 is stimulated has not been fully established [42]. Moreover, related to this group we found the Doa4 deubiquitinating enzyme (Figure 3), which has been associated with cell morphology and actin cytoskeleton defects. In fact, $D O A 4$ had a synthetic genetic interaction with SLA1 [43]. A second subgroup encompasses six mutants, including structural cell wall-related proteins. Three of them are glycosylphosphatidylinositol-anchored proteins (GPIAPs) on the cell surface: Gas1, which is a $\beta-1,3$-glucanosyltransferase; Ecm33, which is linked to cell wall maintenance; and Yps7, an aspartyl protease. The corresponding deletant strains have severe cell wall defects that may explain their high basal Slt2 activation. In fact, the compensatory response elicited in a gas $1 \Delta$ strain has previously been characterized, and it involves a significant induction in MLP1 expression [12]. In agreement with this, gas $1 \Delta$ and $e c m 33 \Delta$ mutants have previously been shown to have a constitutively high level of Slt2 phosphorylation $[44,45]$. Moreover, within this second subgroup we found Las21, an ER membrane protein involved in the synthesis of the GPI core structure. The absence of this protein leads to global cell wall defects. Functionally linked to Las21, the protein Arv1 was identified (Figure 3). This protein is involved in sphingolipid metabolism and has recently been related to the process of GPI synthesis and anchoring [46]. Finally, two proteins related to chitin metabolism, Chs6, which is involved in chitin synthase Chs3 activity, and Chs1 (chitin synthase I), which is required for repairing the chitin septum during cytokinesis [7] were uncovered in our screening. The identification of these mutants is significant since, due to functional redundancy and the existence of gene families, the deletion of certain individual genes encoding cell wall-related proteins does not usually lead to observable phenotypes. A third subset includes pmt1 $\Delta$, hoc $1 \Delta$ and alg6 $\Delta$ strains. All of them encode mannosyltransferase activities, and their selection in the screening is consistent with the finding that protein glycosylation of cell surface proteins is important for cell wall assembly $[7,47]$. Interestingly, transcriptional responses to $\mathrm{O}$ - and $\mathrm{N}$-glycosylation defects in yeast include the fingerprint of the cell wall damage transcriptional profile $[48,49]$.

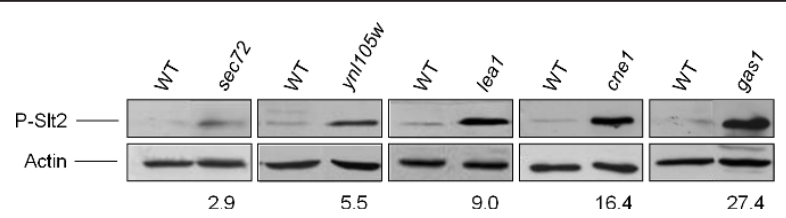

Figure 2 Representative examples of yeast mutants with increased levels of Slt2 phosphorylation. Exponential phase cultures of the indicated yeast strains were taken and processed for immunoblotting as described under "Methods". Western blots detecting the phosphorylated form of SIt2 (P-Slt2) and actin as loading control are shown. Numbers correspond to the P-Slt2 fold-change obtained from densitometric quantification of the P-SIt2 bands from Western blots normalized with respect to the actin bands, using the values of the wildtype strain as reference (fold-change set to 1.0). 


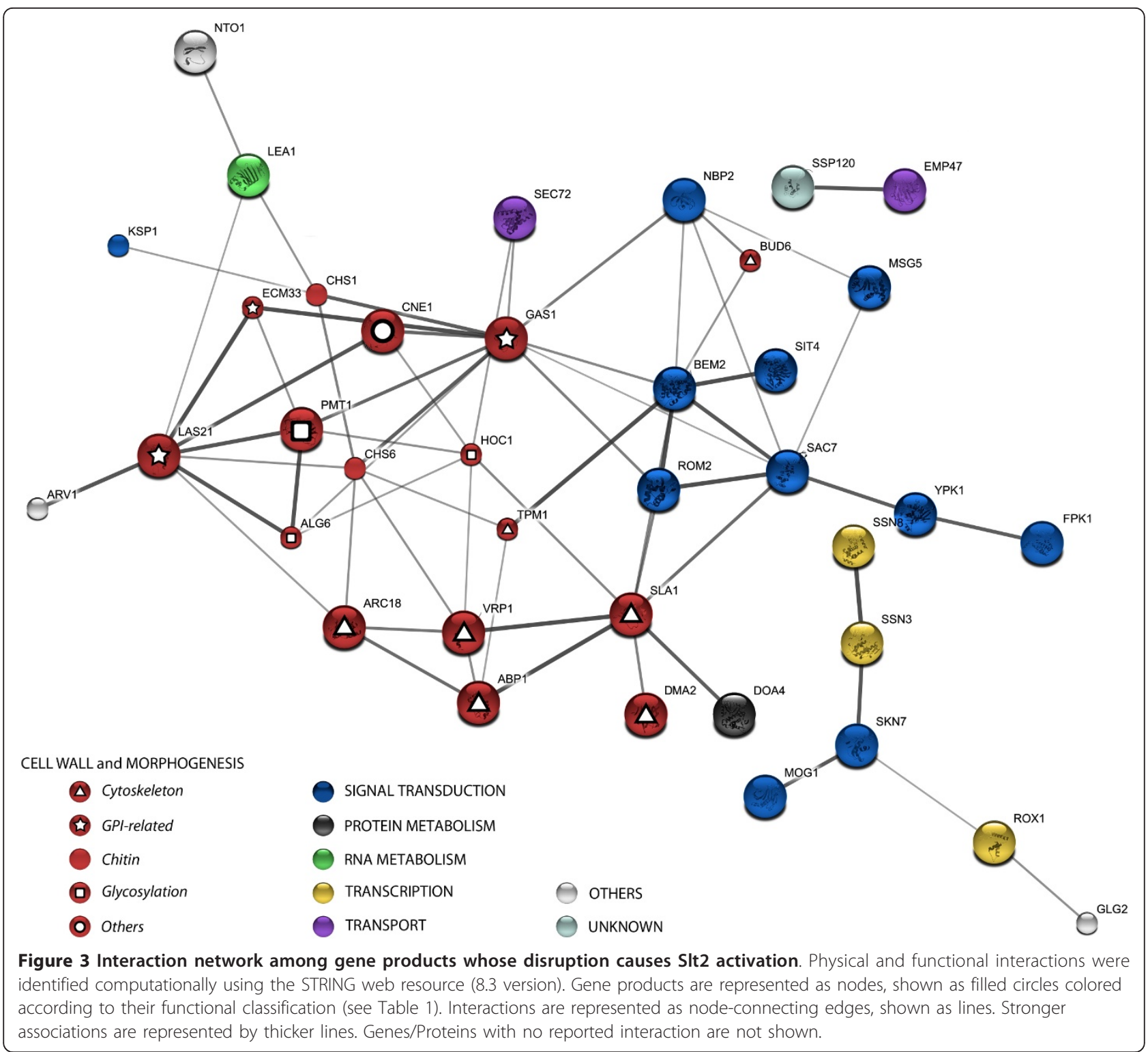

In S. cerevisiae, mannosyltransferases are highly redundant, being included in different protein families $[7,50]$. The identification of the abovementioned proteins is indicative of their specific importance in cell wall homeostasis.

Within the group of mutants involved in cellular signaling, we have identified several well-known negative regulators of Slt2 activity, such as the Rho1 GTPase activators Sac7 and Bem2, and protein phosphatases Sit4 and Msg5, which negatively regulate the pathway acting on Pkc1p and Slt2p, respectively $[51,52]$. We also identified Rom2 in spite of being an activator (Rho1 GEF) of the CWI pathway and the protein kinase Ypk1, a regulator linking sphingolipid signaling and CWI pathway [53]. The effect on Slt2 activation in a rom $2 \Delta$ strain has previously been described [54]. These authors hypothesized that rom $2 \Delta$ mutants have a defective cell wall due to a decreased activity of the CWI pathway, and this alteration may triggers Slt2 activation through Rom2independent mechanisms. The singling out of these mutants further validates our screening for discovering novel potential regulators of the CWI pathway. This is the case of Nbp2, Ksp1, Fpk1, Mog1 and Skn7. Nbp2 acts as a negative regulator of the HOG pathway by recruiting Ptc1 phosphatase to Hog1 [55], and has been involved in cortical ER inheritance via Slt2 [56], the protein kinase Ksp1 has recently been linked to filamentous growth in haploid yeast cells [57], and Fpk1 (flippase kinase 1) regulates phospholipid membrane translocation [58]. Skn7 is a multifunctional transcription factor, as reflected by its 
ability to partner a variety of other transcriptional regulators under different conditions. It has previously been shown that Skn7 may be activated by Rho1p in response to cell wall stress [59], whereas Mog1p is a protein involved in nucleocytoplasmic transport. At the same time, Mog1 is required for optimal recruitment of Skn7 to specific gene promoters [60]. The fact that Slt2 is hyperactivated in these mutants suggests novel connections between the CWI pathway and the cellular processes controlled by these elements.

Regarding the set of mutants related to transcription, many of the proteins identified are involved in RNA polymerase II dependent transcription controlling responses to a variety of conditions such as, heat stress (RTR1), oxidative stress (YPR115w) and anaerobic conditions (ROX1). Additionally, as visualized in the network map (Figure 3), there is a connection between the transcription factors Skn7 and Rox1, with both participating in the transcriptional response to oxidative stress [61]. Also, we identified two components of a module of the mediator complex (Ssn3 and Ssn8), involved in the regulation of Skn7 activity [62]. The appearance of these mutants in our study suggests a functional link between them and the CWI pathway. These insights enable an association to be made between this MAPK pathway and additional stressful cellular events. In this regard, it is also worth to mention that some of the mutants identified in our screening have previously shown altered sensitivity to osmotic stress ( $p h m 8 \Delta, g l g 2 \Delta$ and $m r s 3 \Delta)$ or heat stress

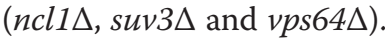

A connection has been described between the CWI pathway and endoplasmic reticulum (ER) stress. When a cell encounters conditions that increase misfolded proteins, the Unfolded Protein Response (UPR) is activated to compensate for high levels of ER stress [63]. The Slt2 MAPK pathway is activated during ER stress [23], while UPR is activated by signaling through the CWI pathway during cell wall stress [64]. Moreover, a second pathway, the ER stress surveillance pathway (ERSU) independent of the UPR, has recently been linked to Slt2 activation [65]. According to our results, in some of the selected mutants these mechanisms of Slt2 activation could be involved. In fact, Emp47 is required for the export of specific glycoprotein cargo from the endoplasmic reticulum, Sec72 is involved in targeting secretory proteins to ER, and Orm 2 is a protein related to lipid homeostasis and protein quality control, being required for resistance to agents that induce UPR [66]. In addition, Orm2 interacts with Slt2, but the biological significance of this interaction is still unknown [67]. Finally, we found the cne 1 mutant to be associated with ER quality control mechanisms. Cne1 is a calnexin homologue of Saccharomyces cerevisiae that may play a part in the degradation of misfolded glycoproteins.
The identification of deletant strains in genes whose function remains uncharacterized and those not previously associated to cell wall integrity, both recording an increase in Slt2 phosphorylation, was of special interest since they could be putatively associated with cell wall construction or regulation. To further investigate this possibility, a phenotypical analysis was conducted on the 11 deletant strains corresponding to genes of unknown function and 15 without clear cell wall phenotypes reported in yeast databases. Thus, the sensitivity to Congo red, caspofungin, hygromycin B, caffeine and SDS was determined. These compounds affect cell integrity through different modes of action, whereby the dye Congo red interferes with proper cell wall assembly [68], caspofungin consists of a $\beta$-1,3-glucan synthase inhibitor, hygromycin B hypersensitivity has been associated with glycosylation defects [69], SDS is a detergent that affects membrane stability and also, indirectly, cell wall construction (increased accessibility) [70], and caffeine is a substance that indirectly activates the CWI pathway in a TOR1-dependent fashion [71]. Eventually, 15 out of 26 strains analyzed displayed altered sensitivity in at least one of the tests described (Table 2), suggesting that the activation of the CWI pathway in these mutants could be due to direct or indirect cell wall alterations. Interestingly, these mutants generally had more than one phenotype supporting the existence of relevant cell wall damage. In contrast, identification of mutants without apparent cell wall defects could be related to the possibility of CWI pathway activation by other stimuli. In this regard, the coordination under specific growth conditions between the CWI and other regulatory MAPK pathways has been extensively reported [20,25]. Further supporting this, Harrison and colleagues [42] suggested that the activation of the CWI pathway by different stresses, rather than operating in a linear "top-down" manner, would provide lateral inputs that impact this regulatory pathway at different levels. Moreover, recent findings connect Slt2 MAPK to DNA damage responses [72].

\section{Differences in chitin content between mutants with Slt2 activation}

The yeast cell wall normally contains approximately $2 \%$ chitin. However, certain mutations affecting cell wall stability increase chitin levels to as much as $20 \%$ of total wall polymers [73]. As this emergency response for cell wall repair is dependent on CWI pathway signaling, it prompted us to assess this response in the whole group of 64 mutants with basal activation of the pathway. Chitin content was measured by means of flow cytometry after staining the cells with the chitin-binding dye, Calcofluor white $(C W)$. This is a reliable and sensitive method for chitin determination, since it has been established a linear relationship between fluorescence 
Table 2 Sensitivity test on yeast deletant strains

\begin{tabular}{|c|c|c|c|c|c|}
\hline \multirow[b]{2}{*}{$\begin{array}{l}\text { ORF/ } \\
\text { Gene }\end{array}$} & \multicolumn{5}{|c|}{ Sensitivity } \\
\hline & $\begin{array}{l}\text { Congo } \\
\text { red }\end{array}$ & Caspofungin & SDS & Caffeine & $\begin{array}{c}\text { Hygromycin } \\
\text { B }\end{array}$ \\
\hline YCRO9OC & - & - & - & - & - \\
\hline YDL173W & - & - & $S$ & SS & - \\
\hline YDR290W & SSSS & SSS & $\mathrm{S}$ & - & SS \\
\hline YGR022C & - & SSS & $S$ & - & - \\
\hline YLR250W & - & - & - & - & - \\
\hline YLR338W & SSSS & $\mathbf{R}$ & SS & SSSSS & SSSSS \\
\hline $\begin{array}{l}\text { YMR119W- } \\
\text { A }\end{array}$ & - & - & - & - & - \\
\hline YNL058C & - & - & - & - & - \\
\hline YNL105W & - & - & - & - & - \\
\hline YNR014W & - & - & - & $\mathbf{R}$ & - \\
\hline YPL158C & - & SSS & - & SS & - \\
\hline$E R C 1$ & - & - & - & - & - \\
\hline FES1 & SSSSS & - & SSSSS & SSSSS & - \\
\hline FPK1 & - & - & - & $\mathbf{R}$ & - \\
\hline GAT2 & SS & - & $S$ & - & SSSSS \\
\hline GLG2 & - & - & - & - & - \\
\hline KSP1 & - & - & - & - & - \\
\hline LEA1 & SS & - & - & SSSS & SSS \\
\hline MOG1 & - & SS & SS & SS & SSSSS \\
\hline MSP1 & - & - & - & - & - \\
\hline PHM8 & - & - & - & - & SSS \\
\hline RMD11 & - & - & $S$ & - & - \\
\hline$R O X 1$ & - & - & - & - & SSSS \\
\hline SEC72 & - & - & - & - & - \\
\hline SUV3 & - & - & - & - & SSS \\
\hline YPR115W & - & - & - & - & - \\
\hline
\end{tabular}

Sensitivity to Congo red $(100 \mu \mathrm{g} / \mathrm{ml})$, Caspofungin $(40 \mathrm{ng} / \mathrm{ml})$, SDS $(200 \mu \mathrm{g} / \mathrm{ml})$, Caffeine $(12 \mathrm{mM}$ ) and Hygromycin B $(50 \mu \mathrm{g} / \mathrm{ml})$ using a spot dilution assay (see Methods for details) is shown. Hypersensitivity levels are shown as the number of spot dilutions ("S") in which no cell growth is scored. " $\mathrm{R}$ " refers to a resistant phenotype and " - " indicates no difference in growth relative to the wild-type strain. Genes of unknown function are grouped in the upper part of the table.

from yeast cells stained with $\mathrm{CW}$ measured by flow cytometry and the biochemical determination of chitin [74]. Remarkably, 19 ( 30\%) strains contained more than twice the amount of chitin than the wild-type strain (Figure 4), denoting that a cell wall compensatory mechanism is triggered in these cells. As described above for Slt2 activation, a wide range of chitin content was observed, suggesting that increased deposition of this polymer is adapted to specific cellular requirements. In some of these mutants $(n b p 2 \Delta$, sla $1 \Delta, \operatorname{vrp} 1 \Delta$, $y \operatorname{lr} 338 w \Delta$, gas $1 \Delta$ and arc18 $\Delta$ ) elevated chitin levels and genetic interactions with mutations involved in chitin synthesis have previously been described [75]. In contrast, the remaining 45 mutants did not record an evident increase in CW binding. Interestingly, about half of those mutants with increased chitin levels have been related functionally to cell wall and/or morphogenesis, whereas within the group of mutants lacking significantly increased chitin deposition only $18 \%$ were assigned to this functional group. These data suggest a functional link between the chitin-related mechanism and activation of the CWI pathway by cell wall and morphogenesis alterations. Eight out of ten mutants with maximum Slt 2 phosphorylation, most of them cell wall related (see Table 1), recorded higher chitin levels, reinforcing the idea that this polymer plays a key role in yeast for salvaging the cell under conditions that jeopardize cell integrity.

However, the identification of mutants with no significant variations in the amount of chitin indicates that CWI pathway activation could be due to alternative stimuli or internal inputs on this signaling route. In this regard, gat $2 \Delta$ and lea $1 \Delta$ mutants are two examples of special interest because they have strong Slt2 activation without affecting their chitin content (Table 1 and Figure 5a), despite they showed cell wall alterations. GAT2 encodes for a poorly characterized putative zinc finger transcription factor, while $L E A 1$ gene product is involved in RNA splicing, although its null mutation shows synthetic sick interaction with several cell wall related genes, such as $C H S 1$ or CHS5 [40]. In order to gain further insights into the origin of pathway activation in these mutants, we decided to construct double mutants deleting ROM2 or BCK1 in the gat $2 \Delta$ and lea $1 \Delta$ backgrounds. Rom 2 is the major GEF for Rho1 that is responsible for relaying signals from cell surface to Rho1 for its activation [76,77], while Bck1 is the first element of the CWI pathway MAPK module. These mutants allowed us to distinguish whether the phosphorylation of Slt2 was the result of cell wall stress sensing or otherwise took place directly through the MAPK module of the route independently of upstream elements. After investigating Slt2 phosphorylation in single (gat $2 \Delta$ and lea $1 \Delta$ ) and double (gat $2 \Delta \operatorname{rom} 2 \Delta$; gat $2 \Delta b c k 1 \Delta$; lea $1 \Delta$ rom $2 \Delta$; lea $1 \Delta b c k 1 \Delta$ ) mutants, it was evident that MAPK activation was fully dependent on Bck1, whereas the lack of Rom2 did not affect the Slt2 activation in gat $2 \Delta$ and lea $1 \Delta$ strains (Figure $5 \mathrm{~b}$ ). Nevertheless, participation of other Rho1 GEFs like Rom1 or Tus1 can not be ruled out. This is in contrast to the activation of the CWI pathway by the cell wall stress caused by Congo red, in which Rom 2 is demanded for Slt2 activation [37]. These results support the notion that particular cell wall alterations could trigger specific adaptive responses through the CWI pathway.

\section{MAPK phosphorylation vs. transcriptional activation}

An important aspect we wanted to address about the functioning of the CWI pathway was the association between the magnitude of Slt2 phosphorylation and the concomitant effect on gene expression. To achieve this goal, a selected group of mutants, representing different 


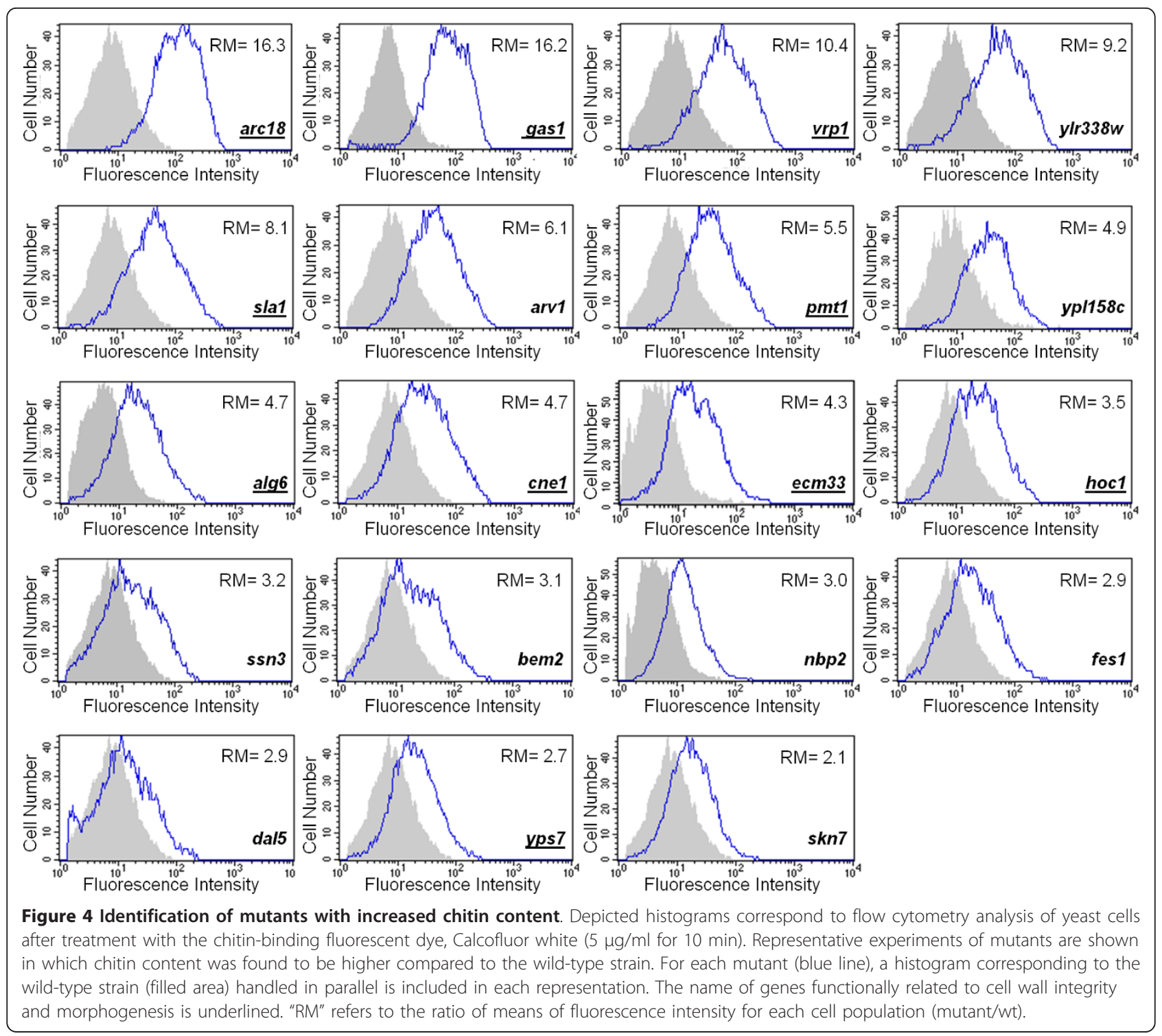

levels of Slt2 activation, were transformed with a reporter construction where the promoter region of the $M L P 1$ gene was fused to the lac $Z$ coding sequence $\left(M L P 1_{P}-l a c Z\right)$ and transcriptional activation was studied under standard growth conditions by measuring $\beta$-Galactosidase activity. As shown in Figure 6a, a good correlation between the expression levels of $M L P 1$ and Slt2 phosphorylation (Pearson's correlation coefficient of 0.8 ) was observed except for the mutant lea1 $\Delta$, in which the reporter expression was significantly lower than expected from the MAPK phosphorylation status. Similar results were obtained when using the CWP1 promoter, another reporter of the CWI pathway (Figure $6 \mathrm{~b}$ ). In this regard, comparable behavior was recently described for the mutant $m s g 5 \Delta$ in which Slt2 phosphorylation is not associated with Rlm1-dependent transcription [78].
On the basis of this observation, the existence of additional $S$. cerevisiae mutants with the same behavior cannot be ruled out.

In contrast to the group of mutants described above with increased levels of phospho-Slt2, another group of 110 mutants selected in the screening did not have detectable differences in Slt2 phosphorylation with respect to the wild-type strain. In order to confirm the nourseothricin resistance of these strains, we transformed them all with the reporter construct $\left(M L P 1_{P^{-}}\right.$ NAT1) and carried out minimal inhibitory concentration (MIC) assays using a microdilution method. Eventually, 38 mutant strains recorded higher antibiotic MIC values than that of the wild-type (Additional file 2), confirming the phenotype of nourseothricin resistance, whereas all the other mutants behaved the same as the wild-type 

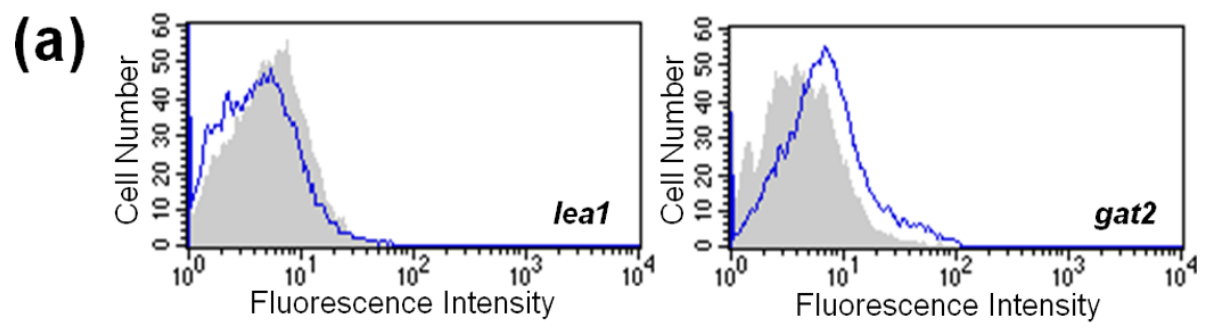

(b)
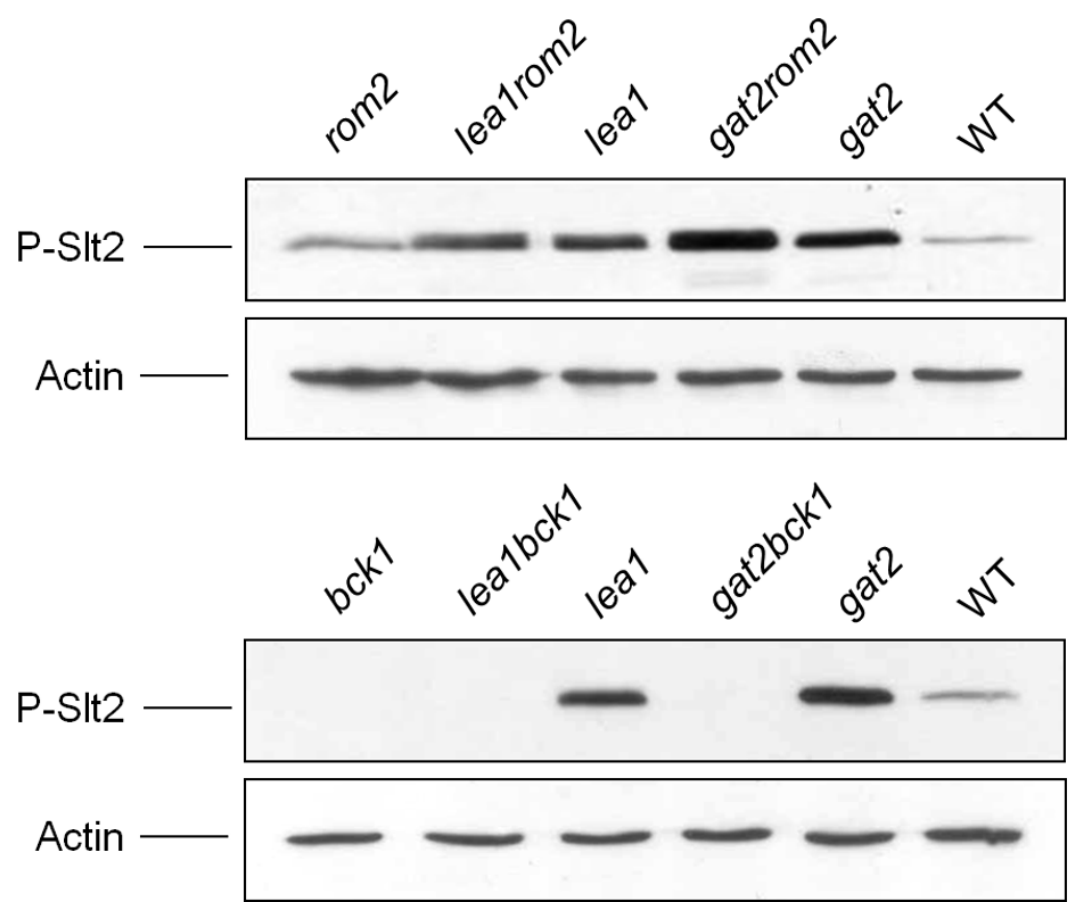

Figure 5 Slt2 activation in gat2 $\Delta$ and lea1 $\Delta$ mutants is not transmitted via Rom2 nor related to variations in chitin content. (a) Analysis of chitin content of gat $2 \Delta$ and lea $1 \Delta$ cells after Calcofluor white staining by means of flow cytometry as described in Figure 4 . (b) Western blots detecting Phospho-Slt2 (P-Slt2) and actin as loading control in total protein extracts from single (gat $2 \Delta$ and lea $1 \Delta$ ) and double (lear $\Delta$ rom $2 \Delta$, gat $2 \Delta r o m 2 \Delta$, lea $1 \Delta b c k 1 \Delta$ and gat $2 \Delta b c k 1 \Delta$ ) mutant strains.

strain. Bearing in mind that this phenotype was also confirmed for the 64 mutants with increased phosphorylation of Slt2, this group probably includes mutants with antibiotic resistance by non-CWI-related mechanisms, such as alternative effects on MLP1 expression or intrinsic antibiotic resistance.

To further investigate the molecular mechanism involved in the group of antibiotic resistant strains without detectable variation in phospho-Slt2 levels, the $M L P 1_{P}$-lacZ reporter was used to monitor levels of expression of $M L P 1$ in this set of mutants. For the majority of the mutants, $M L P 1$ expression levels were low and in general higher than the wild-type strain (Figure 7a). However, mutant strains $s s d 1 \Delta$ and $p m t 2 \Delta$ had very high levels of $M L P 1$ expression (Figure 7a) in spite of very slight, if any, Slt2 activation (Figure 7b). Pmt2 catalyzes the first step in O-mannosylation of target proteins [79] and SSD1 has been linked to cell wall integrity [80,81]. To elucidate a possible participation of the CWI pathway in the activation of the gene expression in these mutants, we proceeded to generate $p m t 2 \Delta s l t 2 \Delta, p m t 2 \Delta \operatorname{rm} 1 \Delta$, ssd $1 \Delta$ slt $2 \Delta$ and $s s d 1 \Delta r \operatorname{lm} 1 \Delta$ double mutants. By using these strains transformed with plasmids containing transcriptional fusions of MLP1,CWP1 and SED1 to lacZ, we were able to delimit the requirement of the CWI MAPK and its main transcription factor (Rlm1) for the observed transcriptional up-regulation. As shown in Figure 8a, gene activation in the absence of both CWI pathway elements, Slt2 or Rlm1, was completely annulled compared to $p m t 2 \Delta$ and $s s d 1 \Delta$ single mutants. These results point to the existence of situations where undetectable changes in MAPK activation (Figure $7 b$ ) give rise to remarkable consequences at gene expression levels. As further proof of the essentiality of Slt 2 activity in the transcriptional 


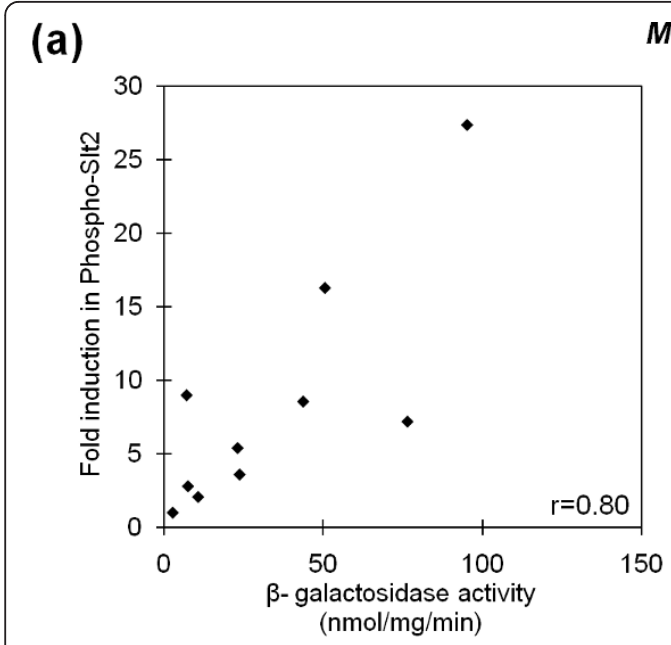

\section{MLP1-lacZ}

(b)

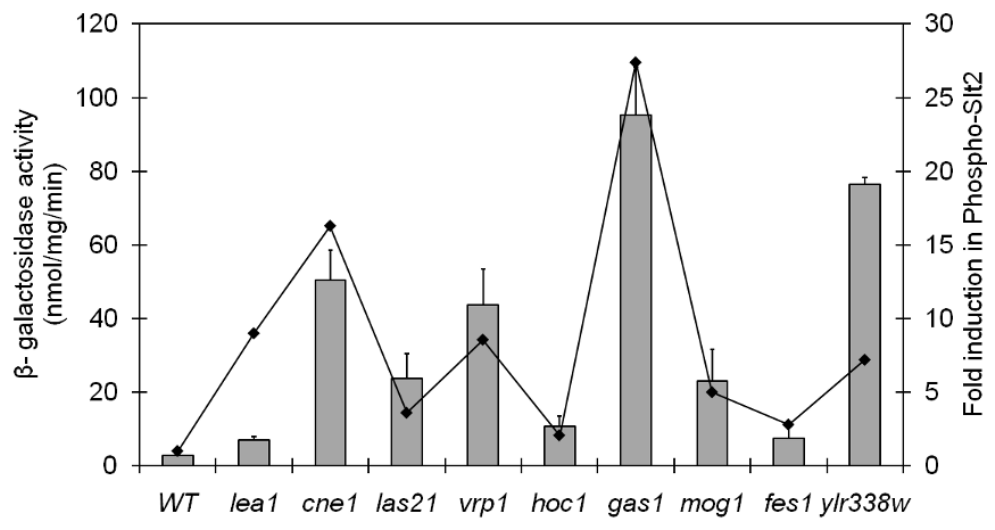

\section{CWP1-lacZ}
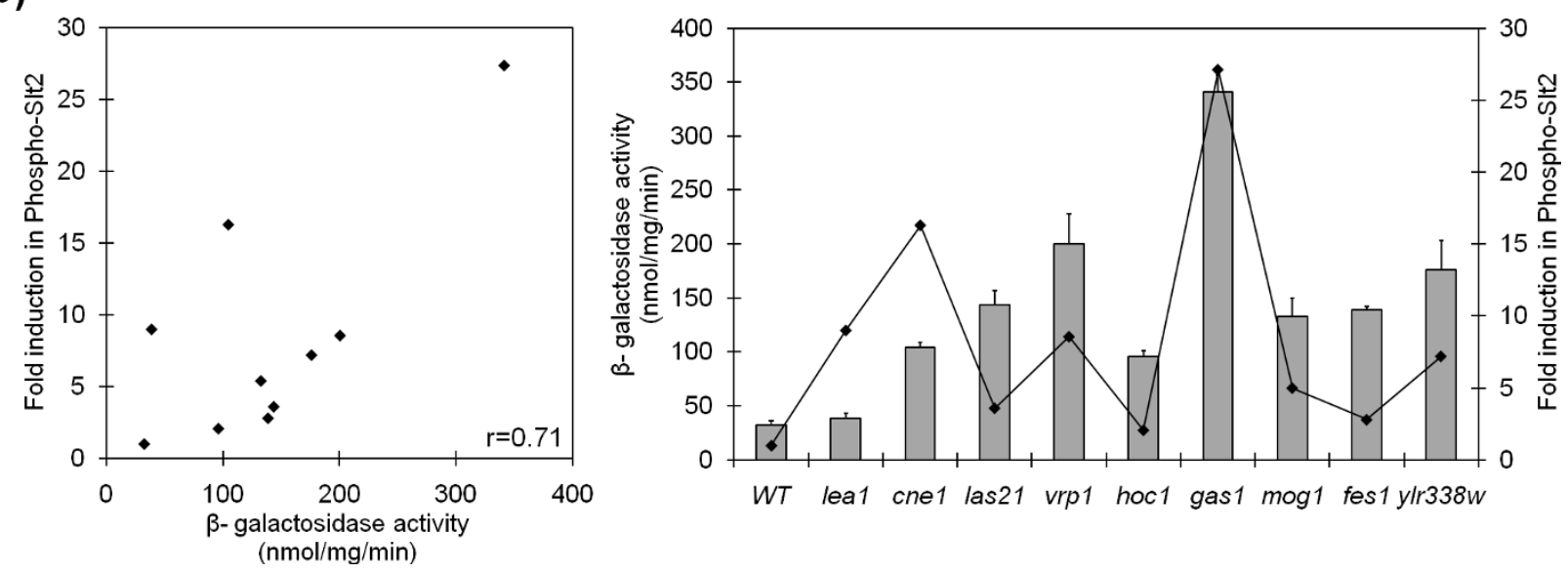

Figure 6 Examination of transcriptional activation and SIt2 phosphorylation in mutants selected from the screening. Bars correspond to levels of MLP1-lacZ (a) and CWP1-lacZ (b) expression observed in the indicated deletion mutants and the wild-type strain. Three independent experiments were carried out to calculate the means of $\beta$-galactosidase activity and standard deviations. The line graph represents the foldchange in SIt2 phosphorylation for each mutant relative to the values observed in the wild-type strain (1x) as described in Table 1. 2D scatter plots of fold-change in phospho-Slt2 vs transcriptional activation are shown on the left side, including the Pearson's correlation coefficient ( $r$ ).

response observed in the pmt $2 \Delta$ and $s s d 1 \Delta$ strains, we took advantage of two mutant forms of MAPK Slt2. The first was a variant K54R, consisting of a mutation within the ATP-binding site, which blocks the catalytic activity of the protein. The second one (TA/YF) eliminates the phosphorylation of Slt2 by upstream MAPKKs Mkk1/ Mkk2. Both alleles, borne on centromeric plasmids, were unable to restore $M L P 1_{P}$-lac $Z$ expression in pmt $2 \Delta$ slt $2 \Delta$ and $s s d 1 \Delta$ slt $2 \Delta$ strains (Figure $8 \mathrm{~b}$ ), indicating that signaling through active Slt2 was imperative. These results sustain a mechanism of MAPK signaling in which high levels of transcriptional induction through $\mathrm{Rlm} 1$ are not necessarily associated with MAPK phosphorylation levels. This is relevant for CWI pathway-related studies since the phosphorylation status of Slt 2 might not always reflect the real pathway outcomes. Further studies will be necessary to characterize the mechanism involved.

\section{Conclusions}

The fine and specific tuning of transduction pathways to ensure yeast cell survival under adverse environmental conditions is essential. Our study contributes significantly to a better understanding of how yeast cell responses to those conditions that jeopardize cell wall integrity or alter its regulation through the CWI pathway. This work has allowed us to identify, at genomic scale, a cluster of genes whose absence induces the transcriptional activation associated with the cell wall integrity compensatory mechanism. Increased levels of phosphorylated MAPK Slt2 were found in a large group of these mutants, in agreement with their direct or indirect association with cell integrity. In fact, the main cluster of genes within this group is related to cell wall biogenesis, morphogenesis and signal transduction. Of special interest are those genes detected by the screening that have not previously been involved in 


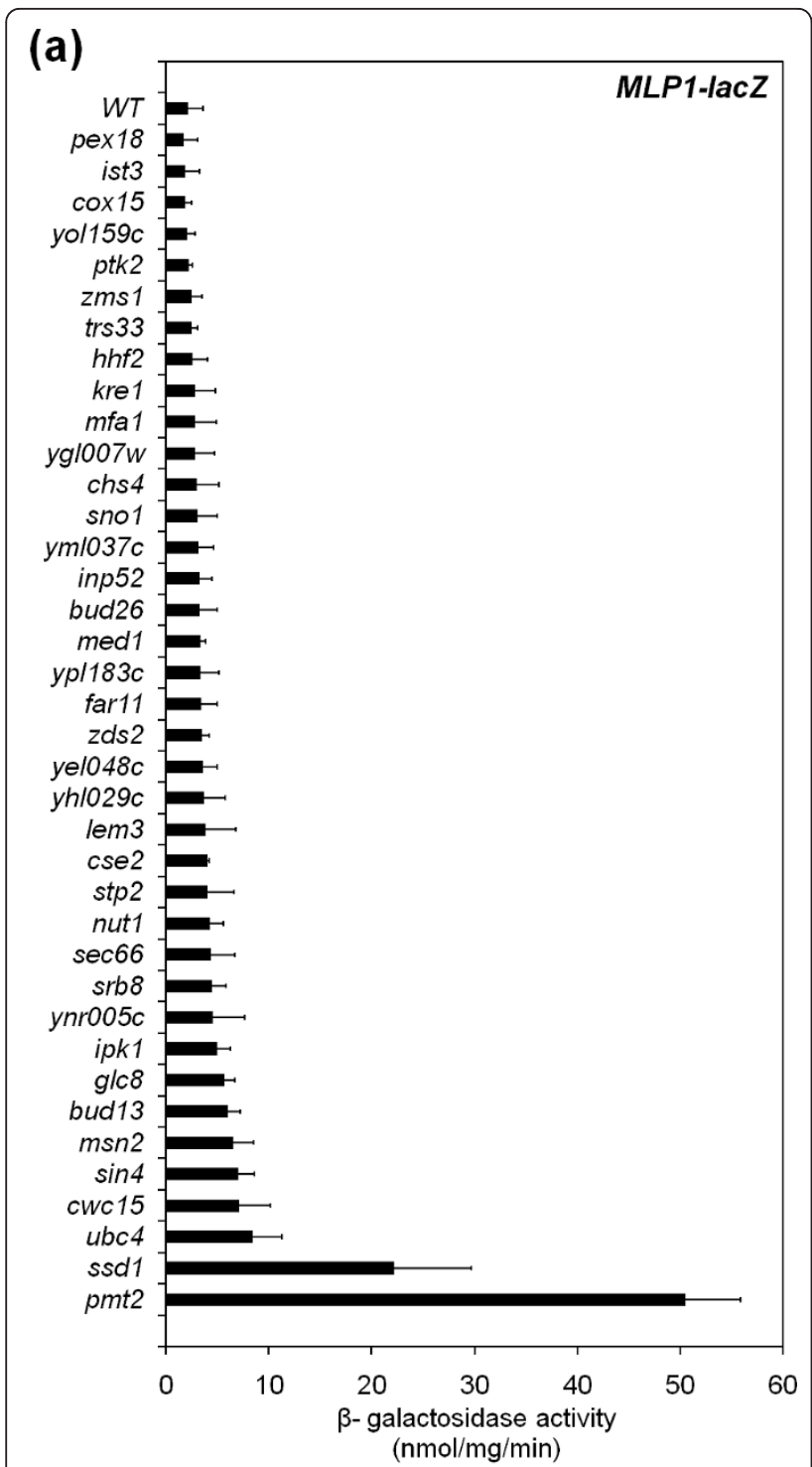

(b)

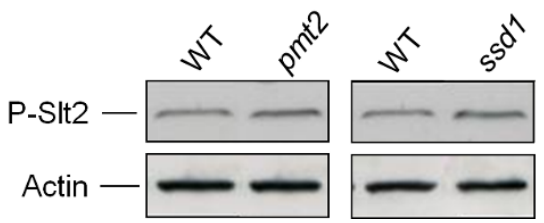

Figure 7 Examination of $M L P 1$ expression in mutants lacking Slt2 activation. (a) Expression of MLP1-lacZ was determined in wild-type and the indicated deletant strains growing to mid-log phase in a rich medium. Each value represents the mean and standard deviation of three independent transformants. (b) Slt2 phosphorylation was examined by immunoblotting total extracts from exponential cultures of the wild-type strain and pmt2 $\Delta$ and ssd $1 \triangle$ mutants growing in YEPD with an anti-phospho-p44/p42 MAPK antibody. The protein load was monitored using a mouse anti-actin $\mathrm{mAb}$
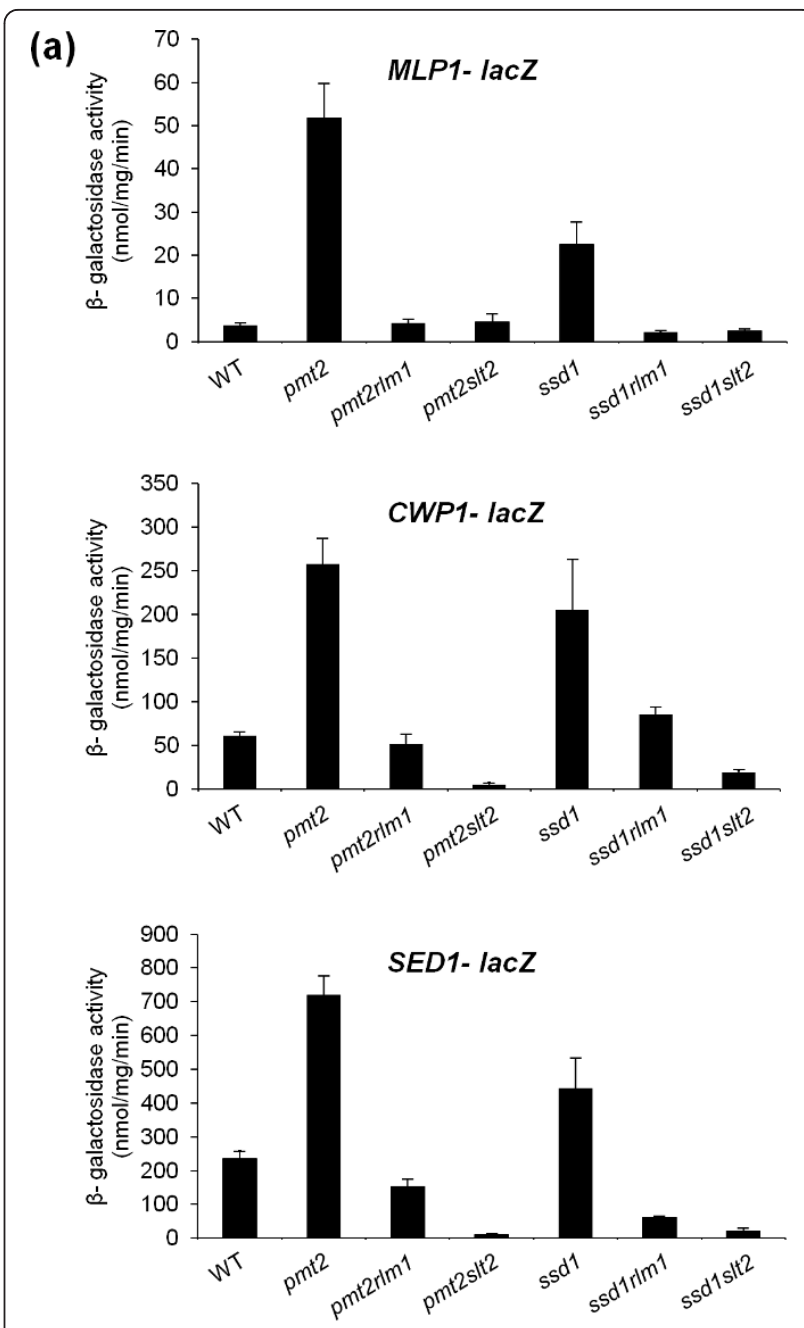

(b)

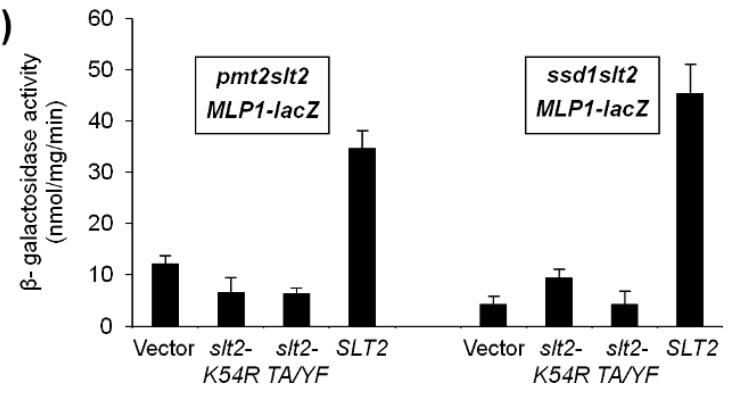

Figure 8 Transcriptional response observed in mutants pmt2 $\Delta$ and ssd1 $1 \Delta$ is dependent on Slt2 activity. (a) Expression of MLP1lacZ, CWP1-lacZ and SED1-lacZ was determined in wild-type strain and $p m t 2 \Delta, p m t 2 \Delta r / m 1 \Delta, p m t 2 \Delta s / 2 \Delta$, ssd $1 \Delta$, ssd $1 \Delta r / m i \Delta$ and ssd1 $1 \Delta$ st $2 \Delta$ mutant cells growing in a rich medium under standard conditions. (b) The MLPI-lacZ reporter plasmid was co-transformed with centromeric plasmids bearing the wild-type SLT2 allele, inactive mutant alleles of SLT2 (slt2/mpk1-K54R and s/t2/mpk1-TAYF) or the empty vector (pRS315) into pmt2 $\Delta s / t 2 \Delta$ and ssd1 $\Delta s / t 2 \Delta$ strains, and $\beta$-galactosidase activity was measured in crude extracts. Each value represents the mean and standard deviation of three independent transformants. 
cell wall integrity, particularly those of unknown function, as well as genes related to transcription, RNA and protein metabolism and transport.

Although an increase in chitin content has been described as one of the effector mechanisms within the compensatory response, our results show that there is not always a correlation between activation of the CWI pathway and chitin levels. This effect is probably dependent on the stimuli involved. In fact, within the group of mutants with higher chitin levels, the functional group of genes related to cell wall and morphogenesis is overrepresented, suggesting a functional link between the activation of the chitin deposition-mediated mechanism and cell wall defects.

Another aspect of interest is the lack of uniformity of the magnitude of MAPK activation and the transcriptional outputs in the mutants analyzed, suggesting that their modulation could be relevant for cellular adaptation to specific circumstances. Although levels of MAPK activation generally correlate with transcriptional up-regulation, there are also, and unexpectedly, mutants with a transcriptional activation dependent on a functional Slt2 MAPK and the transcription factor Rlm1, despite not having significant levels of phospho-Slt2. Bearing in mind that this phenomenon could take place in other circumstances, MAPK pathway related studies should seek information on both MAPK activation and gene expression to discover whether the pathway plays a role under specific conditions.

\section{Methods}

\section{Strains and media}

Experiments were performed with the full collection of Saccharomyces cerevisiae strains (BY4741 background, $M A T \mathbf{a}$; his $3 \Delta 1$; leu $2 \Delta 0$; met $15 \Delta 0$; ura $3 \Delta 0$ ) individually deleted in all of the ORFs identified in this organism (4840) that were replaced by the Geneticin resistancecodifying KanMX4 module. This collection was provided by Euroscarf (Germany). Double mutants slt $2 \Delta p m t 2 \Delta$, slt $2 \Delta s s d 1 \Delta, \operatorname{rlm} 1 \Delta p m t 2 \Delta, \operatorname{rlm} 1 \Delta s s d 1 \Delta$, gat $2 \Delta \operatorname{rom} 2 \Delta$, lea $1 \Delta \operatorname{rom} 2 \Delta$, gat $2 \Delta b c k 1 \Delta$ and lea $1 \Delta b c k 1 \Delta$ were primarily obtained by directly replacing the genes $S L T 2$ or RLM 1 and ROM 2 or BCK1 in the corresponding pmt $2 \triangle$ or $s s d 1 \Delta$ and gat $2 \Delta$ or lea $1 \Delta$ single-deletant-strains, respectively, with the HIS3 marker using the SFH PCRbased method described by Wach and colleagues [82]. Alternatively, slt2 $2:: H I S 3, \operatorname{rlm} 1 \Delta:: H I S 3, \operatorname{rom} 2 \Delta:: H I S 3$ or bck1 $1 \Delta:: H I S 3$ strains constructed in the wild-type BY4742 background (MAT $\alpha)$ were crossed with the single deletants of interest to generate the corresponding heterozygous disruptants. After sporulation and tetrad analyses of these strains with standard yeast genetic techniques, haploid double-mutant segregants were selected. Correct ORF replacements were verified by PCR.
For routine cultures, $S$. cerevisiae was grown on YEPD ( $2 \%$ glucose, $2 \%$ peptone, $1 \%$ yeast extract) or SC-Ura/ Leu medium $(0.17 \%$ yeast nitrogen base, $0.5 \%$ ammonium sulfate, $2 \%$ glucose and uracil/leucine drop-out mix).

The Escherichia coli strain used as plasmid host was $\mathrm{DH} 5 \alpha$. For selective growth, bacteria were grown on LB medium containing $100 \mathrm{mg} / \mathrm{l}$ ampicillin.

Standard procedures were used for yeast genetic and DNA manipulations.

\section{DNA manipulation and plasmids}

General DNA manipulation methods were performed using standard techniques [83]. Whenever necessary, sequence verification of plasmid constructions was carried out on an automated 3730 DNA Analyzer (Applied Biosystems). The plasmid pJS05 [38] contains the promoter region of the gene $M L P 1$ (YKL161c) fused to the NAT1 ORF (encoding for resistance to the antibiotic nourseothricin). Plasmids $M L P 1_{P}$-lacZ, CWP $1_{P}$-lacZ and $S E D 1_{P}$-lacZ including the promoter region of $M L P 1$, $C W P 1$ and SED1 genes fused to lacZ have been described previously [17]. Plasmids bearing the Slt2/Mpk1 alleles TA/YF (p2190), K54R (p2193) and the wild-type gene (p2188) were previously described [35].

\section{Screening for yeast mutants displaying increased basal MLP1 expression}

Initially, the full collection of yeast mutant strains distributed in seventy-five 96-well microtiter plates (Nunclon) were transformed with the plasmid pJS05 following a protocol of microtiter plate transformation [84], using $\mathrm{SC}$-Ura as selection medium. A new set of plates containing $100 \mu \mathrm{l}$ of fresh SC-Ura medium were then inoculated with $5 \mu \mathrm{l}$ of the original transformation cultures and allowed to grow at $28^{\circ} \mathrm{C}$ for $24 \mathrm{~h}$ to be used to inoculate the plates for the screening for MLP1 induction. Thus, $5 \mu \mathrm{l}$ of these pre-inoculums were used to inoculate the definitive set of microtiter plates containing $95 \mu \mathrm{l}$ of YEPD plus $300 \mu \mathrm{g} / \mathrm{ml}$ of nourseothricin (Werner BioAgents, Germany) per well. The plates were incubated in a static culture at $28^{\circ} \mathrm{C}$ for $48-72 \mathrm{~h}$ and growth was determined by measuring absorbance at $550 \mathrm{~nm}$ in each well with a microplate reader (Model 680, Bio-Rad). The parameters described above, including incubation times, inoculum size and antibiotic concentration, were previously optimized in order to prevent the growth of the wild-type strain (unaltered $M L P 1$ expression).

\section{Nourseothricin susceptibility testing}

Selected yeast mutants and the wild-type strain, as control, were individually transformed with the plasmid pJS05 following standard yeast genetic methods. 
Antibiotic susceptibility assays were performed in 96-well sterile plates, filling each well with $95 \mu \mathrm{l}$ of YPD containing decreasing (twofold) concentrations of the antibiotic nourseothricin, ranging from $500 \mu \mathrm{g} / \mathrm{ml}$ to $0.78 \mu \mathrm{g} / \mathrm{ml}$ (including a growth control without nourseothricin for each serial dilution). Finally, each well (except for sterility controls) was inoculated with $5 \mu \mathrm{l}$ of a cell suspension containing approximately $10^{4}$ cells from an exponentially growing culture corresponding to each transformed strain under evaluation (overnight growth in SC-Ura and refreshed in YEPD). The plates were incubated in a static culture at $28^{\circ} \mathrm{C}$ for $40 \mathrm{~h}$, and growth was determined by measuring absorbance at $550 \mathrm{~nm}$ in each well with a microplate reader. Each experiment was performed with at least two independent transformants.

\section{Western blot assays}

Yeast cells were grown in YEPD overnight at $24^{\circ} \mathrm{C}$ to an optical density of $0.8-1\left(\mathrm{OD}_{600}\right)$. The culture was then refreshed to $0.2 \mathrm{OD}_{600}$ and grown at $24^{\circ} \mathrm{C}$ for $6 \mathrm{~h}$. The procedures used for immunoblot analyses, including cell collection and lysis, collection of proteins, fractionation by SDS-polyacrylamide gel electrophoresis, and transfer to nitrocellulose membranes, have been described previously [39]. Phosphorylated Slt2/Mpk1 was detected using anti-phospho-p44/p42 MAPK (thr ${ }^{202} /$ tyr $^{204}$; Cell Signaling Technology, Beverly, MA). To monitor protein loading, actin levels were determined using mouse antiactin mAb C4 (ICN Biomedicals, Aurora, OH). For the quantification of the bands from autoradiography films, densitometric analysis was performed using the Quantity One package (Bio-Rad Laboratories). For each sample (mutant strain), a fold-change of Phospho-Slt2 regarding the levels observed in the wild-type strain was calculated as the ratio of the intensity of the P-Slt2 band normalized by the amount of actin for each sample (mutant/ wt). Experiments were carried out at least in duplicate.

\section{$\beta$-galactosidase reporter assays}

Yeast transformants were grown overnight in an SC-Ura or SC-Ura-Leu medium, as required, at $24^{\circ} \mathrm{C}$ and then the culture was refreshed in YEPD to $0.2 \mathrm{OD}_{600}$ and grown at $24^{\circ} \mathrm{C}$ for $6 \mathrm{~h}$. Yeast cell extracts were prepared by harvesting cells by centrifugation from $5 \mathrm{ml}$ of culture. The cells were then resuspended in $250 \mu \mathrm{l}$ of breaking buffer (100 $\mathrm{mM}$ Tris- $\mathrm{HCl} \mathrm{pH}=8,1 \mathrm{mM}$ Dithiothreitol, 20\% glycerol), and glass beads (Glasperlen ca. $1 \mathrm{~mm}$, Sartorius AG, Germany) were added to break cells in a Fast-Prep machine. Finally, extracts were clarified by centrifugation and protein concentrations were measured using the Bradford method. $\beta$-galactosidase assays were performed using the crude extracts obtained as described previously [85], scaling the protocol to a 96-well microtiter plate format. 5-10 $\mu \mathrm{l}$ of cell extract was mixed with $90-95 \mu \mathrm{l}$ of $\mathrm{Z}$ buffer plus $\beta$-mercaptoethanol (0.03\%) and $20 \mu \mathrm{l}$ of $o$-nitrophenyl- $\beta$ $\mathrm{D}$-galactopyranoside (ONPG) (4 $\mathrm{mg} / \mathrm{ml}$ in Z buffer). The absorbance of the enzymatic reaction was measured at $415 \mathrm{~nm}$ on a microplate reader (Model 680, Bio-Rad) after at least $10 \mathrm{~min}$ of incubation at $30^{\circ} \mathrm{C}$ and the addition of $50 \mu \mathrm{l}$ of $1 \mathrm{M} \mathrm{Na}_{2} \mathrm{CO}_{3}$ to stop the reaction. $\beta$-galactosidase activity was expressed as nmoles of ONPG converted $/ \mathrm{min}$ $\mathrm{ute} / \mathrm{mg}$ of protein. Experiments were performed at least in triplicate involving three independent yeast transformants.

\section{Cell wall phenotypic analyses}

Yeast cells were grown overnight at $24^{\circ} \mathrm{C}$ in YEPD to mid-log phase. The culture was diluted to an $\mathrm{OD}_{600}$ of around 0.2 and then incubated at $24^{\circ} \mathrm{C}$ in YEPD for $4 \mathrm{~h}$. These cultures were subsequently diluted again to 0.2 (approximately $15 \times 10^{3}$ cells in $5 \mu \mathrm{l}$ ) and four fivefold dilution series were prepared. Finally, $5 \mu \mathrm{l}$ of each dilution was spotted on to YEPD solid media containing $100 \mu \mathrm{g} / \mathrm{ml}$ Congo red (Merck), $12 \mathrm{mM}$ caffeine (Sigma), $200 \mu \mathrm{g} / \mathrm{ml}$ SDS (Duchefa Biochemie), $50 \mu \mathrm{g} / \mathrm{ml}$ Hygromycin B (Roche), and $40 \mathrm{ng} / \mathrm{ml}$ caspofungin (kindly provided by Merck), using a multi-blot replicator (V\&P Scientific, San Diego, CA). Growth was monitored on the plates after $2-3$ days at $30^{\circ} \mathrm{C}$.

\section{Flow cytometry and Microscopic analysis}

Yeast strains were grown overnight at $24^{\circ} \mathrm{C}$ in YEPD to mid-log phase. The culture was diluted to an $\mathrm{OD}_{600}$ of around 0.2 and then incubated at $24^{\circ} \mathrm{C}$ in YEPD for $4 \mathrm{~h}$. After this time, $1 \mathrm{ml}$ of cells was collected, washed with PBS and stained with Calcofluor white (Fluorescent Brightener 28, Sigma-Aldrich, St. Louis, MO) at a final concentration of $5 \mu \mathrm{g} / \mathrm{ml}$ for $10 \mathrm{~min}$ in darkness. For the flow cytometry analysis of chitin content using Calcofluor staining, cells were analyzed with a BD LSR flow cytometer (Becton Dickinson) by acquiring fluorescence through a 380 LP filter. Cell viability was monitored by staining cells with propidium iodide $(0.05 \mathrm{mg} / \mathrm{ml})$ acquiring fluorescence through a 670 LP filter. As experimental control, stained yeasts were also analyzed by fluorescence microscopy using a Nikon TE2000 fluorescence inverted microscope equipped with a CCD camera. Digital images were acquired with an Orca C4742-95-12ER camera (Hamamatsu Photonics, Japan) and processed with Aquacosmos Imaging System software.

\section{Additional material}

Additional file 1: Complete set of yeast mutants with increased levels of Slt2 phosphorylation. Representative Western blot experiments of yeast mutants in which MAPK SIt2 was constitutively activated are shown. 
Additional file 2: Yeast mutant strains resistant to nourseothricin without increased levels of Phospho-Slt2. Functional information on the genes whose disruption leads to antibiotic resistance without detectable SIt2 phosphorylation is shown.

\section{Abbreviations}

CWI: cell wall integrity; MAPK: mitogen activated protein kinase; GPI: glycosylphosphatidylinositol; WT: wild-type.

\section{Acknowledgements}

This work was supported by projects BIO2007-67821 and BIO2010-22146 (MICINN, Spain), S-SAL-0246/2006 (CAM, Spain), GR58/08 (Ref. 920640) from UCM and Research Networking Programme (06-RNP-132; European Science Foundation). CN is head of the Merck Sharp \& Dohme special chair in genomics and proteomics. Thanks are due to all members of the UCM-PCM Genomic Unit for their collaboration in managing the collection of yeast mutants and A. Vázquez of the Centro de Citometría y Microscopía de Fluorescencia (UCM, Spain) for expert help in flow cytometry. We also thank members of Research Unit 4 at the Department of Microbiology for fruitful discussions, as well as María Molina and Humberto Martin for critical reading. Plasmids bearing SLT2/MPK1 alleles were kindly provided by Dr. D. Levin (Boston University).

\section{Authors' contributions}

PA was responsible for the assessment of levels of Slt2 phosphorylation, $\beta$-galactosidase assays, flow cytometry, phenotypic analysis and fluorescence microscopy. SD-M conducted the setting-up and subsequent screening for nourseothricin resistance with the collection of yeast mutants, and participated in fluorescence microscopy assays. RG carried out bioinformatic analysis and figure design. $\mathrm{CN}$ participated in the coordination of the study. JMR-P and JA conceived the study, participated in the design and analysis of experimental data and wrote the manuscript. All authors read and approved the final manuscript.

Received: 21 February 2011 Accepted: 2 August 2011

Published: 2 August 2011

\section{References}

1. Qi M, Elion EA: MAP kinase pathways. J Cell Sci 2005, 118:3569-3572.

2. Chen RE, Thorner J: Function and regulation in MAPK signaling pathways: lessons learned from the yeast Saccharomyces cerevisiae. Biochim Biophys Acta 2007, 1773:1311-1340.

3. Lee BN, Elion EA: The MAPKKK Ste11 regulates vegetative growth through a kinase cascade of shared signaling components. Proc Natl Acad Sci USA 1999, 96:12679-12684.

4. Torres L, Martin H, Garcia-Saez MI, Arroyo J, Molina M, Sanchez M, Nombela C: A protein kinase gene complements the lytic phenotype of Saccharomyces cerevisiae lyt2 mutants. Mol Microbiol 1991, 5:2845-2854.

5. Levin DE, Bowers B, Chen CY, Kamada Y, Watanabe M: Dissecting the protein kinase C/MAP kinase signalling pathway of Saccharomyces cerevisiae. Cell Mol Biol Res 1994, 40:229-239.

6. Klis FM, Boorsma A, De Groot PW: Cell wall construction in Saccharomyces cerevisiae. Yeast 2006, 23:185-202.

7. Lesage G, Bussey H: Cell wall assembly in Saccharomyces cerevisiae. Microbiol Mol Biol Rev 2006, 70:317-343.

8. Cabib E, Blanco N, Grau C, Rodriguez-Pena JM, Arroyo J: Crh1p and Crh2p are required for the cross-linking of chitin to beta(1-6)glucan in the Saccharomyces cerevisiae cell wall. Mol Microbiol 2007, 63:921-935.

9. Cabib E, Farkas V, Kosik O, Blanco N, Arroyo J, McPhie P: Assembly of the yeast cell wall. Crh1p and Crh2p act as transglycosylases in vivo and in vitro. J Biol Chem 2008, 283:29859-29872.

10. Latge JP: Tasting the fungal cell wall. Cell Microbiol 2010, 12:863-872.

11. Popolo L, Gualtieri T, Ragni E: The yeast cell-wall salvage pathway. Med Mycol 2001, 39(Suppl 1):111-121.

12. Lagorce A, Hauser NC, Labourdette D, Rodriguez C, Martin-Yken H, Arroyo J, Hoheisel JD, Francois J: Genome-wide analysis of the response to cell wall mutations in the yeast Saccharomyces cerevisiae. J Biol Chem 2003, 278:20345-20357.
13. Agarwal AK, Rogers PD, Baerson SR, Jacob MR, Barker KS, Cleary JD, Walker LA, Nagle DG, Clark AM: Genome-wide expression profiling of the response to polyene, pyrimidine, azole, and echinocandin antifungal agents in Saccharomyces cerevisiae. J Biol Chem 2003, 278:34998-35015.

14. Boorsma A, De Nobel H, ter Riet B, Bargmann B, Brul S, Hellingwerf KJ, Klis FM: Characterization of the transcriptional response to cell wall stress in Saccharomyces cerevisiae. Yeast 2004, 21:413-427.

15. Garcia R, Bermejo C, Grau C, Perez R, Rodriguez-Peña JM, Francois J, Nombela C, Arroyo J: The global transcriptional response to transient cell wall damage in Saccharomyces cerevisiae and its regulation by the cell integrity signaling pathway. J Biol Chem 2004, 279:15183-15195.

16. Rodriguez-Peña JM, Perez-Diaz RM, Alvarez S, Bermejo C, Garcia R, Santiago C, Nombela C, Arroyo J: The 'yeast cell wall chip' - a tool to analyse the regulation of cell wall biogenesis in Saccharomyces cerevisiae. Microbiology 2005, 151:2241-2249.

17. Garcia R, Rodriguez-Peña JM, Bermejo C, Nombela C, Arroyo J: The high osmotic response and cell wall integrity pathways cooperate to regulate transcriptional responses to zymolyase-induced cell wall stress in Saccharomyces cerevisiae. J Biol Chem 2009, 284:10901-10911.

18. Bermejo C, Garcia R, Straede A, Rodriguez-Peña JM, Nombela C, Heinisch JJ, Arroyo J: Characterization of sensor-specific stress response by transcriptional profiling of wsC 1 and mid2 deletion strains and chimeric sensors in Saccharomyces cerevisiae. OMICS 2010, 14:679-688.

19. Smits GJ, Van Den EH, Klis FM: Differential regulation of cell wall biogenesis during growth and development in yeast. Microbiology 2001 147:781-794.

20. Levin DE: Cell wall integrity signaling in Saccharomyces cerevisiae. Microbiol Mol Biol Rev 2005, 69:262-291.

21. Heinisch JJ: Baker's yeast as a tool for the development of antifungal kinase inhibitors-targeting protein kinase $C$ and the cell integrity pathway. Biochim Biophys Acta 2005, 1754:171-182.

22. Bonilla M, Cunningham KW: Mitogen-activated protein kinase stimulation of $\mathrm{Ca}(2+)$ signaling is required for survival of endoplasmic reticulum stress in yeast. Mol Biol Cell 2003, 14:4296-4305.

23. Chen Y, Feldman DE, Deng C, Brown JA, De Giacomo AF, Gaw AF, Shi G, Le QT, Brown JM, Koong AC: Identification of mitogen-activated protein kinase signaling pathways that confer resistance to endoplasmic reticulum stress in Saccharomyces cerevisiae. Mol Cancer Res 2005, 3:669-677.

24. Serrano R, Martin $\mathrm{H}$, Casamayor A, Arino J: Signaling alkaline $\mathrm{pH}$ stress in the yeast Saccharomyces cerevisiae through the Wsc1 cell surface sensor and the SIt2 MAPK pathway. J Biol Chem 2006, 281:39785-39795.

25. Rodriguez-Peña JM, Garcia R, Nombela C, Arroyo J: The high-osmolarity glycerol (HOG) and cell wall integrity (CWI) signalling pathways interplay: a yeast dialogue between MAPK routes. Yeast 2010, 27:495-502.

26. Verna J, Lodder A, Lee K, Vagts A, Ballester R: A family of genes required for maintenance of cell wall integrity and for the stress response in Saccharomyces cerevisiae. Proc Natl Acad Sci USA 1997, 94:13804-13809.

27. Ketela T, Green R, Bussey H: Saccharomyces cerevisiae mid2p is a potential cell wall stress sensor and upstream activator of the PKC1-MPK1 cell integrity pathway. J Bacteriol 1999, 181:3330-3340.

28. Rajavel M, Philip B, Buehrer BM, Errede B, Levin DE: Mid2 is a putative sensor for cell integrity signaling in Saccharomyces cerevisiae. Mol Cell Biol 1999, 19:3969-3976.

29. Truman AW, Millson SH, Nuttall JM, King V, Mollapour M, Prodromou C, Pearl LH, Piper PW: Expressed in the yeast Saccharomyces cerevisiae, human ERK5 is a client of the Hsp90 chaperone that complements loss of the Slt2p (Mpk1p) cell integrity stress-activated protein kinase. Eukaryot Cell 2006, 5:1914-1924.

30. Abe J, Kusuhara M, Ulevitch RJ, Berk BC, Lee JD: Big mitogen-activated protein kinase 1 (BMK1) is a redox-sensitive kinase. J Biol Chem 1996, 271:16586-16590.

31. Yan C, Luo H, Lee JD, Abe J, Berk BC: Molecular cloning of mouse ERK5/ $B M K 1$ splice variants and characterization of ERK5 functional domains. J Biol Chem 2001, 276:10870-10878.

32. Watanabe $Y$, Takaesu G, Hagiwara M, Irie K, Matsumoto K: Characterization of a serum response factor-like protein in Saccharomyces cerevisiae, RIm1, which has transcriptional activity regulated by the Mpk1 (SIt2) mitogen-activated protein kinase pathway. Mol Cell Biol 1997, 17:2615-2623. 
33. Baetz K, Moffat J, Haynes J, Chang M, Andrews B: Transcriptional coregulation by the cell integrity mitogen-activated protein kinase Slt2 and the cell cycle regulator Swi4. Mol Cell Biol 2001, 21:6515-6528.

34. Jung US, Sobering AK, Romeo MJ, Levin DE: Regulation of the yeast RIm1 transcription factor by the Mpk1 cell wall integrity MAP kinase. Mol Microbiol 2002, 46:781-789.

35. Kim KY, Truman AW, Levin DE: Yeast Mpk1 mitogen-activated protein kinase activates transcription through Swi4/Swi6 by a noncatalytic mechanism that requires upstream signal. Mol Cell Biol 2008, 28:2579-2589.

36. Garcia-Rodriguez $L$, Valle R, Duran A, Roncero C: Cell integrity signaling activation in response to hyperosmotic shock in yeast. FEBS Lett 2005, 579:6186-6190.

37. Bermejo C, Rodriguez E, Garcia R, Rodriguez-Peña JM, Rodriguez de la Concepcion ML, Rivas C, Arias P, Nombela C, Posas F, Arroyo J: The sequential activation of the yeast HOG and SLT2 pathways is required for cell survival to cell wall stress. Mol Biol Cell 2008, 19:1113-1124.

38. Rodriguez-Peña JM, Diez-Muñiz S, Nombela C, Arroyo J: A yeast strain biosensor to detect cell wall-perturbing agents. J Biotechnol 2008, 133:311-317.

39. Martin H, Rodriguez-Pachon JM, Ruiz C, Nombela C, Molina M: Regulatory mechanisms for modulation of signaling through the cell integrity Slt2mediated pathway in Saccharomyces cerevisiae. J Biol Chem 2000, 275:1511-1519.

40. Tong AH, Lesage G, Bader GD, Ding H, Xu H, Xin X, Young J, Berriz GF, Brost $R L$, Chang $M$, et al: Global mapping of the yeast genetic interaction network. Science 2004, 303:808-813.

41. Szklarczyk D, Franceschini A, Kuhn $M$, Simonovic $M$, Roth $A$, Minguez $P$, Doerks T, Stark M, Muller J, Bork P, et al: The STRING database in 2011: functional interaction networks of proteins, globally integrated and scored. Nucleic Acids Res 2011, 39:D561-D568.

42. Harrison JC, Zyla TR, Bardes ES, Lew DJ: Stress-specific activation mechanisms for the "cell integrity" MAPK pathway. J Biol Chem 2004, 279:2616-2622.

43. Fiorani $P$, Reid RJ, Schepis A, Jacquiau HR, Guo H, Thimmaiah P, Benedetti P, Bjornsti MA: The deubiquitinating enzyme Doa4p protects cells from DNA topoisomerase I poisons. J Biol Chem 2004, 279:21271-21281.

44. De Nobel H, Ruiz C, Martin H, Morris W, Brul S, Molina M, Klis FM: Cell wall perturbation in yeast results in dual phosphorylation of the Slt2/Mpk1 MAP kinase and in an SIt2-mediated increase in FKS2-lacZ expression, glucanase resistance and thermotolerance. Microbiology 2000, 146:2121-2132.

45. De Groot PW, Ruiz C, Vazquez de Aldana CR, Duenas E, Cid VJ, del Rey F, Rodriguez-Peña JM, Perez P, Andel A, Caubin J, et al: A genomic approach for the identification and classification of genes involved in cell wall formation and its regulation in Saccharomyces cerevisiae. Comp Funct Genomics 2001, 2:124-142.

46. Kajiwara K, Watanabe $\mathrm{R}$, Pichler $\mathrm{H}$, Ihara K, Murakami S, Riezman $\mathrm{H}$, Funato K: Yeast ARV1 is required for efficient delivery of an early GPI intermediate to the first mannosyltransferase during GPI assembly and controls lipid flow from the endoplasmic reticulum. Mol Biol Cell 2008, 19:2069-2082

47. Lommel M, Strahl S: Protein O-mannosylation: conserved from bacteria to humans. Glycobiology 2009, 19:816-828.

48. Cullen PJ, Xu-Friedman R, Delrow J, Sprague GF: Genome-wide analysis of the response to protein glycosylation deficiency in yeast. FEMS Yeast Res 2006, 6:1264-1273.

49. Arroyo J, Hutzler J, Bermejo C, Ragni E, Garcia-Cantalejo J, Botias P, Piberger H, Schott A, Sanz AB, Strahl S: Functional and genomic analyzes of blocked protein O-mannosylation in baker's yeast. Mol Microbiol 2011, 79:1529-1546

50. Willer T, Valero MC, Tanner W, Cruces J, Strahl S: O-mannosyl glycans: from yeast to novel associations with human disease. Curr Opin Struct Biol 2003, 13:621-630.

51. De la Torre-Ruiz A, Torres J, Arino J, Herrero E: Sit4 is required for proper modulation of the biological functions mediated by Pkc1 and the cell integrity pathway in Saccharomyces cerevisiae. J Biol Chem 2002, 277:33468-33476.

52. Flandez M, Cosano IC, Nombela C, Martin H, Molina M: Reciprocal regulation between SIt2 MAPK and isoforms of Msg5 dual-specificity protein phosphatase modulates the yeast cell integrity pathway. $J$ Biol Chem 2004, 279:11027-11034.

53. Schmelzle T, Helliwell SB, Hall MN: Yeast protein kinases and the RHO1 exchange factor TUS1 are novel components of the cell integrity pathway in yeast. Mol Cell Biol 2002, 22:1329-1339.

54. Lorberg A, Jacoby JJ, Schmitz HP, Heinisch JJ: The PH domain of the yeast GEF Rom2p serves an essential function in vivo. Mol Genet Genomics 2001, 266:505-513.

55. Mapes J, Ota IM: Nbp2 targets the Ptc1-type $2 \mathrm{C}$ Ser/Thr phosphatase to the HOG MAPK pathway. EMBO J 2004, 23:302-311.

56. Du Y, Walker L, Novick P, Ferro-Novick S: Ptc1p regulates cortical ER inheritance via SIt2p. EMBO J 2006, 25:4413-4422.

57. Bharucha N, Ma J, Dobry CJ, Lawson SK, Yang Z, Kumar A: Analysis of the yeast kinome reveals a network of regulated protein localization during filamentous growth. Mol Biol Cell 2008, 19:2708-2717.

58. Nakano K, Yamamoto T, Kishimoto T, Noji T, Tanaka K: Protein kinases Fpk1p and Fpk2p are novel regulators of phospholipid asymmetry. Mol Biol Cell 2008, 19:1783-1797.

59. Alberts AS, Bouquin N, Johnston LH, Treisman R: Analysis of RhoA-binding proteins reveals an interaction domain conserved in heterotrimeric $G$ protein beta subunits and the yeast response regulator protein Skn7. J Biol Chem 1998, 273:8616-8622.

60. Lu JM, Deschenes RJ, Fassler JS: Role for the Ran binding protein, Mog1p, in Saccharomyces cerevisiae SLN1-SKN7 signal transduction. Eukaryot Cell 2004, 3:1544-1556.

61. Kelley R, Ideker T: Genome-wide fitness and expression profiling implicate Mga2 in adaptation to hydrogen peroxide. PLoS Genet 2009, 5: e1000488.

62. Lenssen E, Azzouz N, Michel A, Landrieux E, Collart MA: The Ccr4-not complex regulates Skn7 through Srb10 kinase. Eukaryot Cell 2007, 6:2251-2259.

63. Ron D, Walter P: Signal integration in the endoplasmic reticulum unfolded protein response. Nat Rev Mol Cell Biol 2007, 8:519-529.

64. Scrimale T, Didone L, Mesy Bentley KL, Krysan DJ: The unfolded protein response is induced by the cell wall integrity mitogen-activated protein kinase signaling cascade and is required for cell wall integrity in Saccharomyces cerevisiae. Mol Biol Cell 2009, 20:164-175.

65. Babour A, Bicknell AA, Tourtellotte J, Niwa M: A surveillance pathway monitors the fitness of the endoplasmic reticulum to control its inheritance. Cell 2010, 142:256-269.

66. Han S, Lone MA, Schneiter R, Chang A: Orm1 and Orm2 are conserved endoplasmic reticulum membrane proteins regulating lipid homeostasis and protein quality control. Proc Natl Acad Sci USA 2010, 107:5851-5856.

67. Ito T, Chiba T, Ozawa R, Yoshida M, Hattori M, Sakaki Y: A comprehensive two-hybrid analysis to explore the yeast protein interactome. Proc Natl Acad Sci USA 2001, 98:4569-4574.

68. Roncero C, Duran A: Effect of Calcofluor white and Congo red on fungal cell wall morphogenesis: in vivo activation of chitin polymerization. $J$ Bacteriol 1985, 163:1180-1185.

69. Dean N: Yeast glycosylation mutants are sensitive to aminoglycosides. Proc Natl Acad Sci USA 1995, 92:1287-1291.

70. Igual JC, Johnson AL, Johnston LH: Coordinated regulation of gene expression by the cell cycle transcription factor Swi4 and the protein kinase C MAP kinase pathway for yeast cell integrity. EMBO J 1996, 15:5001-5013.

71. Kuranda K, Leberre V, Sokol S, Palamarczyk G, Francois J: Investigating the caffeine effects in the yeast Saccharomyces cerevisiae brings new insights into the connection between TOR, PKC and Ras/CAMP signalling pathways. Mol Microbiol 2006, 61:1147-1166.

72. Bandyopadhyay S, Mehta M, Kuo D, Sung MK, Chuang R, Jaehnig EJ, Bodenmiller B, Licon K, Copeland W, Shales M, et al: Rewiring of genetic networks in response to DNA damage. Science 2010, 330:1385-1389.

73. Klis FM, Mol P, Hellingwerf K, Brul S: Dynamics of cell wall structure in Saccharomyces cerevisiae. FEMS Microbiol Rev 2002, 26:239-256.

74. Hector RF, Braun PC, Hart JT, Kamarck ME: The use of flow cytometry to monitor chitin synthesis in regenerating protoplasts of Candida albicans. J Med Vet Mycol 1990, 28:51-57.

75. Lesage G, Shapiro J, Specht CA, Sdicu AM, Menard P, Hussein S, Tong AH, Boone $\mathrm{C}$, Bussey $\mathrm{H}$ : An interactional network of genes involved in chitin synthesis in Saccharomyces cerevisiae. BMC Genet 2005, 6:8. 
76. Bickle M, Delley PA, Schmidt A, Hall MN: Cell wall integrity modulates RHO1 activity via the exchange factor ROM2. EMBO J 1998, 17:2235-2245.

77. Philip B, Levin DE: Wsc1 and Mid2 are cell surface sensors for cell wall integrity signaling that act through Rom2, a guanine nucleotide exchange factor for Rho1. Mol Cell Biol 2001, 21:271-280.

78. Marin MJ, Flandez M, Bermejo C, Arroyo J, Martin H, Molina M: Different modulation of the outputs of yeast MAPK-mediated pathways by distinct stimuli and isoforms of the dual-specificity phosphatase Msg5. Mol Genet Genomics 2009, 281:345-359.

79. Lussier M, Gentzsch M, Sdicu AM, Bussey H, Tanner W: Protein Oglycosylation in yeast. The PMT2 gene specifies a second protein Omannosyltransferase that functions in addition to the PMT1-encoded activity. J Biol Chem 1995, 270:2770-2775.

80. Kaeberlein M, Guarente L: Saccharomyces cerevisiae MPT5 and SSD1 function in parallel pathways to promote cell wall integrity. Genetics 2002, 160:83-95.

81. Jansen JM, Wanless AG, Seidel CW, Weiss EL: Cbk1 regulation of the RNAbinding protein Ssd1 integrates cell fate with translational control. Curr Biol 2009, 19:2114-2120.

82. Wach A, Brachat A, Alberti-Segui C, Rebischung C, Philippsen P. Heterologous HIS3 marker and GFP reporter modules for PCR-targeting in Saccharomyces cerevisiae. Yeast 1997, 13:1065-1075.

83. Sambrook J, Fritsch EF, Maniatis T: Molecular cloning: A laboratory manual. Cold Spring Harbor, N.Y.: Cold Spring Laboratory Press; 1989.

84. Gietz RD, Woods RA: Transformation of yeast by lithium acetate/singlestranded carrier DNA/polyethylene glycol method. Methods Enzymol 2002, 350:87-96.

85. Amberg DC, Burke DJ, Strathern JN: Methods in Yeast Genetics: A Cold Spring Harbor Laboratory Course Manual John Inglis, Cold Spring Harbor, N.Y.; 2005.

doi:10.1186/1471-2164-12-390

Cite this article as: Arias et al:: Genome-wide survey of yeast mutations leading to activation of the yeast cell integrity MAPK pathway: Novel insights into diverse MAPK outcomes. BMC Genomics 2011 12:390.

\section{Submit your next manuscript to BioMed Central and take full advantage of:}

- Convenient online submission

- Thorough peer review

- No space constraints or color figure charges

- Immediate publication on acceptance

- Inclusion in PubMed, CAS, Scopus and Google Scholar

- Research which is freely available for redistribution

Submit your manuscript at www.biomedcentral.com/submit 